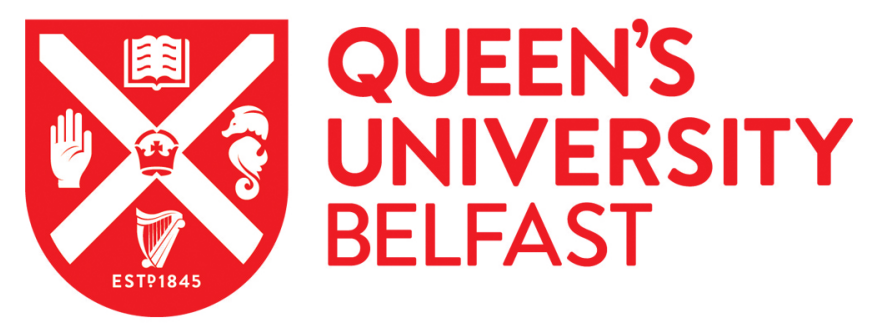

\title{
A mixture of persistent organic pollutants relevant for human exposure inhibits the transactivation activity of the aryl hydrocarbon receptor in vitro
}

Doan, Q. T., Berntsen, H. F., Verhaegen, S., Ropstad, E., Connolly, L., Igout, A., Muller, M., \& Scippo, M-L.

(2019). A mixture of persistent organic pollutants relevant for human exposure inhibits the transactivation activity of the aryl hydrocarbon receptor in vitro. Environmental Pollution , [113098].

https://doi.org/10.1016/j.envpol.2019.113098

\section{Published in:}

Environmental Pollution

\section{Document Version:}

Peer reviewed version

Queen's University Belfast - Research Portal:

Link to publication record in Queen's University Belfast Research Portal

\section{Publisher rights}

Copyright 2019 Elsevier.

This manuscript is distributed under a Creative Commons Attribution-NonCommercial-NoDerivs License

(https://creativecommons.org/licenses/by-nc-nd/4.0/), which permits distribution and reproduction for non-commercial purposes, provided the author and source are cited.

\section{General rights}

Copyright for the publications made accessible via the Queen's University Belfast Research Portal is retained by the author(s) and / or other copyright owners and it is a condition of accessing these publications that users recognise and abide by the legal requirements associated with these rights.

\section{Take down policy}

The Research Portal is Queen's institutional repository that provides access to Queen's research output. Every effort has been made to ensure that content in the Research Portal does not infringe any person's rights, or applicable UK laws. If you discover content in the

Research Portal that you believe breaches copyright or violates any law, please contact openaccess@qub.ac.uk. 
1 A mixture of persistent organic pollutants relevant for human exposure inhibits the

2 transactivation activity of the aryl hydrocarbon receptor in vitro

4 Doan $\mathrm{TQ}^{1}$, Berntsen $\mathrm{HF}^{2,3}$, Verhaegen $\mathrm{S}^{2}$, Ropstad $\mathrm{E}^{2}$, Connolly $\mathrm{L}^{4}$, Igout $\mathrm{A}^{5}$, Muller $\mathrm{M}^{6^{*}}$, Scippo $5 \mathrm{ML}^{1^{*}}$

6 'Laboratory of Food Analysis, FARAH-Veterinary Public Health, University of Liège, Liège, 7 Belgium, 4000;

8 2Department of Production Animal Clinical Sciences, Section of Experimental Biomedicine, 9 NMBU - Faculty of Veterinary Medicine, Oslo, Norway, N-0033; ${ }^{3}$ Department of Administration, Lab Animal Unit, National Institute of Occupational Health P.O.

11 Box 8149 Dep, Oslo, Norway, N-0033;

$12{ }^{4}$ Institute for Global Food Security, School of Biological Sciences, Queen's University Belfast, 13 Northern Ireland, UK, BT7 1NN;

14 Department of biomedical and preclinical sciences, Faculty of Medicine, University of Liège, 15 Liège, Belgium, 4000;

$16{ }^{6}$ GIGA-R, Laboratory for Organogenesis and Regeneration, University of Liège, Liège, Belgium, 17 4000;

18 Corresponding author Scippo ML: mlscippo@uliege.be

19 *Muller M and Scippo ML equally contributed as the last authors.

21 Abstract: While humans are exposed to mixtures of persistent organic pollutants (POPs), their 22 risk assessment is usually based on a chemical-by-chemical approach. To assess the health 23 effects associated with mixed exposures, knowledge on mixture toxicity is required. Several POPs 24 are potential ligands of the Aryl hydrocarbon receptor (AhR), which involves in xenobiotic metabolism and controls many biological pathways. This study assesses AhR agonistic and 
26 antagonistic activities of 29 POPs individually and in mixtures by using Chemical-Activated

27 LUciferase gene eXpression bioassays with 3 transgenic cell lines (rat hepatoma DR-H4IIE, 28 human hepatoma DR-Hep G2 and human mammary gland carcinoma DR-T47-D). Among the 29 29 POPs, which were selected based on their abundance in Scandinavian human blood, only 4 30 exerted AhR agonistic activities, while 16 were AhR antagonists in DR-H4IIE, 5 in DR-Hep G2 31 and 7 in DR-T47-D when tested individually. The total POP mixture revealed to be AhR 32 antagonistic. It antagonized $\mathrm{EC}_{50} \mathrm{TCDD}$ inducing $\mathrm{AhR}$ transactivation at a concentration of 125 and 250 and 500 fold blood levels in DR-H4IIE, DR-T47-D and DR-Hep G2, respectively, although each compound was present at these concentrations lower than their LOEC values. Such values could occur in real-life in food contamination incidents or in exposed populations. In DR-H4IIE, the antagonism of the total POP mixture was due to chlorinated compounds and, in particular, to PCB-118 and PCB-138 which caused $90 \%$ of the antagonistic activity in the POP mixture. The 16 active AhR antagonists acted additively. Their mixed effect was predicted successfully by concentration addition or generalized concentration addition models, rather than independent action, with only two-fold $\mathrm{IC}_{50}$ underestimation. We also attained good predictions for the full doseresponse curve of the antagonistic activity of the total POP mixture.

Keywords: Persistent Organic Pollutants; Aryl hydrocarbon Receptor; Antagonistic activity; Human relevant mixture; Generalized concentration addition model Capsule:

45 A mixture of persistent organic pollutants relevant to human exposure antagonized the 46 transcriptional activity of the Aryl hydrocarbon receptor in vitro, whose activity could be predicted. 


\section{Introduction}

The aryl hydrocarbon receptor $(\mathrm{AhR})$ was originally characterized as a xenobiotic mediator ${ }^{1}$. It is often called the "dioxin receptor" as 2,3,7,8-tetrachlorodibenzo-p-dioxin (TCDD) and several dioxin-like (dl) compounds are AhR agonists. Adverse health effects associated with exposure to these AhR agonists are widely studied, including abnormal reproduction and development, impaired immune system, liver toxicity and cancers ${ }^{2}$.

AhR physiological roles have recently gained more attention since AhR is activated by a wide range of structurally diverse endogenous and exogenous compounds ${ }^{3}$. Also, AhR-deficient rodents suffer from various physiological defects in the immune system ${ }^{4}$, liver ${ }^{5}$, kidney ${ }^{4,6}$, cardiovascular system ${ }^{7}$, urinary bladder ${ }^{8}$, etc. Additionally, AhR homologs are preserved in animal evolution for 600 million years ${ }^{9}$, while invertebrate AhR homologues cannot bind dioxin ${ }^{10}$, indicating that dioxin detection was not the primary role of this protein. Increasing evidence supports important roles of $A h R$ in normal development and homeostasis, while toxicity induced by AhR xenobiotic ligands could be due to perturbation of these normal processes ${ }^{11}$.

Upon ligand binding, the AhR is translocated from cytosol into the nucleus where it joins its dimerization partner, aryl hydrocarbon receptor nuclear translocator (ARNT). This AhR/ARNT complex then binds to a DNA sequence called dioxin responsive element (DRE) to activate the expression of a battery of genes, including both phase I and phase II xenobiotic metabolism enzymes, of which cyp1a1 is the best characterized. Hence, methods measuring cyp1a1 gene expression are widely accepted for determining AhR activation ${ }^{12}$, among which cell-based screening methods such as Chemical-Activated LUciferase gene eXpression (CALUX) are the most common ${ }^{13-15}$. 
73 Many potential AhR ligands are persistent organic pollutants (POPs). POPs are resistant to 74 degradation and widely distributed in the environment. They can be detected in almost every human sample, including fetuses and embryos ${ }^{16}$. They tend to bioaccumulate and biomagnify in living organisms, resulting in toxic health effects to both humans and wildlife ${ }^{17}$.

\section{Presently, chemical risk assessment mainly relies on a chemical-by-chemical approach ${ }^{18}$. In real} life, humans are exposed not to an individual POP, but to highly complex POP mixtures ${ }^{19}$. Understanding mixture toxicity is crucial to assess the potential adverse health effects associated with such real life exposure to mixtures of $\mathrm{POPs}^{20}$. The mixture effects may be additive, synergistic, or antagonistic depending on whether they are equal, stronger, or weaker than the sum of the effects of individual components, respectively ${ }^{21}$. The concepts called "something from nothing" and "a lot from a little" were introduced to describe the mixture effect ${ }^{22}$ and proved in a study on fish when a significant effect was observed for a mixture combining individual compounds each at "no observed effect" concentrations ${ }^{23}$.

Due to the various mixture forms and doses, models using the information of components to predict the combined effects are required. Three mathematical models have been developed for this purpose: i) the concentration addition (CA) model was designed for chemicals with similar mode of actions (MOAs) ${ }^{24}$, but has also proven useful for mixtures with dissimilar compounds ${ }^{23,25,26}$; ii) independent action (IA $)^{27}$, successful in several applications ${ }^{28,29}$, applies for chemicals which act independently and have different MOAs; and iii) the generalized concentration addition (GCA $)^{30}$, a CA modified model, was developed for predicting the effects of mixtures containing partial agonists ${ }^{30-32}$.

In an effort to fill the gap in the knowledge of mixture toxicology, a defined mixture of 29 POPs (total POP mixture) was constructed based on their prominence in blood and/or food and 
breastmilk with the concentration being average blood values from recent Scandinavian studies ${ }^{33-}$ ${ }^{35}$ published prior to $2012^{36}$. To mimic the exposure of cells (in a tissue) to chemicals that are in the blood stream, reporter gene assays involving cancer cell lines from different tissues (liver and mammary gland) and species (rat and human) were used in this study to determine the AhR transcriptional activities of the selected 29 POPs, individually and in mixtures (the total POP mixture and six sub-mixtures $\left.{ }^{36}\right)$. The aims were to (a) assess both AhR agonistic and antagonistic activities after exposing the cell lines to the 29 POPs and to the mixtures, (b) identify the main compound(s) responsible for the observed effects of the mixtures, and (c) predict the mixture activity by applying the three available models (IA, CA and GCA).

\section{Materials and Methods}

\subsection{Chemicals and suppliers}

The total POP and six sub-mixtures were designed and premade by the Norwegian University of Life Sciences, Oslo, Norway as described ${ }^{36}$. The former consists of 29 POPs, where most of them are listed as POPs under the Stockholm Convention on Persistent Organic Pollutants, belonging to three groups: six perfluorinated compounds (PFAAs), seven brominated compounds (BFRs), and 16 chlorinated compounds with seven polychlorinated biphenyls (PCBs) and nine organochlorine pesticides (OCPs). The latter consist of either one single class of compounds (PFAA, $\mathrm{Br}$ and $\mathrm{Cl}$ ) or two combined classes $(\mathrm{Cl}+\mathrm{Br}, \mathrm{Cl}+\mathrm{PFAA}, \mathrm{Br}+\mathrm{PFAA})$. This way of mixture preparation was to enable the study of the effect of adding or removing one chemical group on different endpoints. As the design of the mixtures was focused on compounds occurring at high concentrations, most dl-PCBs (with the exception of PCB-118) and polychlorinated dibenzodioxins/polychlorinated dibenzofurans (PCDD/PCDF) were deliberately excluded. These compounds were also omitted due to their high toxicity at low concentrations in several systems to allow the study of the effect of the non-dl and most prevalent compounds. The components included in the mixtures and their respective concentrations are given in Table S1. 
124 Along with the mixture testing, 29 POPs from the total POP mixture were also examined 125 individually. They were bought from Sigma Aldrich (Missouri, USA) except o-chlordane from 126 Toronto Research Chemicals (North York, Canada) and PCB-118 from Dr Ehrenstorfer 127 (Augsburg, Germany). All chemicals were dissolved in dimethylsulfoxide (DMSO) (Acros 128 Organics, Molinons, France), except HCB in hexane (Merck, Massachusetts, USA).

130 The 29 individual POPs and the mixtures were stored as stock solutions at $-20^{\circ} \mathrm{C}$. Working 131 solutions were prepared from the stock solutions to reach the concentrations mentioned in Table

132 S1. The highest tested concentration was $50 \mu \mathrm{M}$ for all PCBs and PFAAs and $20 \mu \mathrm{M}$ for BFRs 133 except BDE-100, BDE-153, BDE-154 and BDE-209 $(1 \mu \mathrm{M})$ due to stocks available. OCPs were 134 tested at the maximum concentration of $100 \mu \mathrm{M}$ for $\gamma-\mathrm{HCH}$ and dieldrin, or $80 \mu \mathrm{M}$ for all the others.

135 The concentrations for mixture exposure are presented as "fold blood levels", relative to the 136 average contaminant levels found in human blood of the Scandinavian population. The total POP 137 mixture and sub-mixtures were tested at concentrations between the estimated concentrations in 138 human blood and maximum 3000 fold blood levels.

\subsection{Determination of aryl hydrocarbon receptor agonistic and antagonistic activities}

\section{$141 \quad$ 2.2.1. Cell-based assays}

142 Rat and human dioxin responsive (DR) cell lines were used. Rat hepatoma DR-H4IIE cells were 143 from BioDetection System (Amsterdam, The Netherlands) while both human cell lines (hepatoma 144 DR-Hep G2 and mammary gland carcinoma DR-T47-D) were previously home-made (Liege,

145 Belgium $)^{37}$. A vector containing an AhR-controlled luciferase reporter gene was stably integrated 146 into these cells. The vector integrated into DR-H4IIE cells contained four native DREs (from the 147 upstream promotor of the mouse cyp1a1 gene), leading the MMTV (Mouse Mammary Tumour 148 Virus) promoter ${ }^{38}$, while both DR-T47-D and DR-Hep G2 cells were transfected with a vector 
149 containing four synthetic DREs regulating the thymidine kinase promoter ${ }^{37}$. The cells were

150 routinely cultured in MEM $\alpha$ (Thermo Fisher Scientific, Massachusetts, USA) supplemented with

$15110 \% \mathrm{v} / \mathrm{v}$ fetal bovine serum (Greiner, Kremsmünster, Austria), $50 \mathrm{IU} / \mathrm{mL}$ penicillin and $50 \mu \mathrm{g} / \mathrm{mL}$

152 streptomycin (Sigma Aldrich, Missouri, USA), and incubated in a $\mathrm{H}_{2} \mathrm{O}$ saturated atmosphere 153 containing $5 \% \mathrm{CO}_{2}$, at $37^{\circ} \mathrm{C}$.

155 The methodology for the DR-CALUX (Dioxin Responsive Chemical-Activated LUciferase gene 156 eXpression) bioassays was described in detail elsewhere ${ }^{37,39}$. Briefly, cells were first seeded in 157 white clear-bottomed 96 well microplates (Greiner, Kremsmünster, Austria) and incubated for 24h 158 to reach about $90 \%$ of confluence in the well. After 24-hour exposure, the cells were washed with 159 phosphate buffered saline (Sigma Aldrich, Missouri, USA) and treated with lysis solution 160 (containing Triton X100, Sigma Aldrich, Missouri, USA). Luciferin (Promega, Wisconsin, USA) 161 and ATP (Roche Diagnostics, Rotkreuz, Switzerland) were then added to the cell lysate to 162 produce luminescence, which was measured by using a luminometer (ORION II, Berthold

163 Detection System, Pforzheim, Germany). The cells were exposed, in triplicates, to a dilution series 164 of the tested compound/mixture in both agonistic and antagonistic tests. For the latter, the cells were co-exposed with a constant concentration of $15 \mathrm{pM}, 150 \mathrm{pM}$ and $650 \mathrm{pM}$ TCDD corresponding to TCDD EC 50 in DR-H4IIE, DR-T47-D and DR-Hep G2 cells, respectively. In order to verify whether AhR antagonists compete for the same, single site on the AhR with the agonist (TCDD), additional antagonistic tests were performed for selected compounds by co-

170 exposing DR-H4IIE cells to different concentrations of the tested compounds and a constant 171 saturating TCDD concentration $(20 \mathrm{nM})$. Using the agonist (TCDD) at clearly saturating 172 concentrations would make it impossible for a lower affinity antagonist to affect transcriptional 173 activation at all. 
174 All the exposure experiments were repeated at least three times independently. The final 175 concentration of DMSO in the culture medium for the single POPs was $0.2 \%$ and $0.3 \%$ for 176 agonistic and antagonistic tests, respectively, while they were $0.3 \%$ and $0.4 \%$ for the mixtures.

177 For quality control, a TCDD reference curve was performed on each plate.

179 MTT cell viability and LDH cell cytotoxicity were performed along with visual inspection of cell 180 morphology and attachment. The former was carried out in a replicate plate to the DR-CALUX 181 assays. After 24-hour exposure, $25 \mu \mathrm{L}$ MTT dye solution (3-(4,5-dimethylthiazol-2-yl)-2,5182 diphenyltetrazolium bromide, $5 \mathrm{mg} / \mathrm{ml}$, Sigma Aldrich, Missouri, USA) was added into each well,

183 followed by a 4-hour incubation at $37^{\circ} \mathrm{C}$ to form insoluble purple formazan. Then, $100 \mu \mathrm{L}$ 184 isopropanol (Merck, Massachusetts, USA) was added into the plates to dissolve the formazan for 185 two hours. The MTT formazan absorbance was read at 550/630 $\mathrm{nm}$ by a spectrophotometer 186 (ELx800 ${ }^{\mathrm{TM}}$ BioTek, Winooski, USA). Because the MTT data need to be interpreted with caution 187 and are not necessarily related to cell death, we performed the LDH cell cytotoxicity as well. The

188 Pierce $^{\text {TM }}$ LDH Cytotoxicity Assay Kit was purchased from Thermo Fisher Scientific 189 (Massachusetts, USA) and operated according to the manufacturer's instructions (absorbance at $190490 / 630 \mathrm{~nm})$.

\subsubsection{Calculations of $E C_{50}, I C_{50}$ and efficacy $\left(R P C_{M a x}\right)$}

193 Final results were presented as relative responses, i.e. percentages of the cell response to the

194 tested compound/mixture compared to the maximum response of the cells to TCDD on the same 195 plate for agonistic activities, or to spike-in TCDD $\mathrm{EC}_{50}$ for antagonistic activities. Dose-response 196 curves were generated by Graphpad PRISM software, version 7 (San Diego, California, USA) by 197 fitting a four-parameter non-linear regression for agonistic (Eq. 1) or antagonistic (Eq. 2) tests.

$$
\text { (1) } Y_{\text {agonistic }}=B+\frac{x^{H}(T-B)}{x^{H}+E C_{50}{ }^{H}}
$$


(2) $Y_{\text {antagonistic }}=B+\frac{T-B}{1+\frac{x^{H}}{I C_{50}{ }^{H}}}$

199 where $x$ is the concentration of a tested compound/mixture inducing the relative response $Y_{\text {agonistic }}$

200 or $Y_{\text {antagonistic. }} \mathrm{EC}_{50}$ and $\mathrm{IC}_{50}$ are the half maximal effective concentration for an agonist and 201 antagonist, respectively ${ }^{40} . \mathrm{B}=$ bottom, $\mathrm{T}=\mathrm{Top}, \mathrm{H}=$ Hillslope.

204 The lowest observed effect concentration (LOEC) is the lowest tested concentration at which a 205 significant effect $(p<0.05)$ was observed. The maximum observed effect concentration (MOEC) 206 is the lowest tested concentration causing the maximum effect $(p<0.05)$. ANOVA (Graphpad 207 PRISM) was used to determine statistical significance. Prior to ANOVA, tests for homogeneity of 208 variance and normal distribution (transformation if needed) were performed. When no full dose209 response curve was achieved, MOEC was considered as the highest concentration of the test series. Efficacy was determined as $\mathrm{RPC}_{\operatorname{Max}}(\%)$, which is the maximum effect induced by the 211 tested compound ${ }^{40}$ : $A h R$ agonistic $\mathrm{RPC}_{\operatorname{Max}}$ was the maximum relative response of the

212 compound/mixture compared to the maximum TCDD response, while $A h R$ antagonistic $\mathrm{RPC}_{\text {Max }}$ 213 was the minimum relative response observed by the maximum inhibition of the test 214 compound/mixture to the spike-in TCDD $\mathrm{EC}_{50}$. The compound/mixture was accepted as active 215 when its relative response was higher than the threshold level $R P C_{\operatorname{Max}} \geq 10 \%$ for $A h R$ agonists 216 and lower than $\mathrm{RPC}_{\operatorname{Max}} \leq 70 \%$ for AhR antagonists ${ }^{40}$.

\subsubsection{Calculations of the predicted mixture antagonistic effects}

219 Concentration addition (CA). CA model is based on a dilution principle, all the chemicals behave 220 as they are simply the dilution of one another in the mixture. Hence, the effect contribution of one 221 compound to the mixture effect can be totally or partially replaced by the effect of the other. It 222 calculates the effect concentration $\left(\mathrm{IC}_{\mathrm{mix}, \mathrm{j}}\right)$ of the mixture inducing a specific antagonistic effect $\mathrm{j}$ 
223 (from $1 \%$ to $100 \%$ ) by considering the concentration partition $\left(p_{i}\right)$ of compound $i$ and its respective 224 effect concentration (IC $\mathrm{Cij}_{\mathrm{ij}}$ ) inducing the same effect $\mathrm{j}$ (Eq. 3). Previously published formulae were 225 adapted $24,25,29$ :

$$
\text { (3) } I C_{m i x, j}=\left(\sum_{i=1}^{n} \frac{p_{i}}{I C_{i j}}\right)^{-1}
$$

The concentration partition $p_{i}$ can either consider or not the non-active (NA) compounds. Because nonactive compounds do not give $I C_{i j}, n$ is the number of the active compounds.

For each compound $i, I C_{i j}$ inducing the effect $j$ is calculated using its $I C_{i, 50}$ and hillslope $\left(H_{i}\right)$ from 231 their fitted curves using Eq. 4 (Graphpad PRISM):

$$
\text { (4) } I C_{i j}=I C_{i, 50}\left(\frac{j}{100-j}\right)^{1 / H_{i}}
$$

233 Because the CA model allows only the calculation of $I C_{\text {mix.j, }}$, to generate the full dose-response 234 curves, we proposed several possible methods to calculate the hillslope and bottom $\left(\mathrm{H}_{\text {mix }}\right.$ and $B_{\text {mix }}$ ) of the mixture response, while the top was set to $100 \%$ as no response.

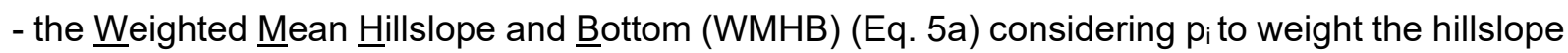
and bottom of the individual compounds:

$$
\text { (5a) } H_{\text {mix }}=\left(\sum_{i=1}^{n} p_{i} H_{i}\right) \frac{100}{n} \text { or } B_{\text {mix }}=\left(\sum_{i=1}^{n} p_{i} B_{i}\right) \frac{100}{n}
$$

239 - the Averaged Hillslope and Bottom $(\mathrm{AvBH})$ considering the average of the hillslope and bottom 240 of the individual compounds (Eq. 5b):

$$
\text { (5b) } H_{\text {mix }}=\frac{\sum_{i=1}^{n} H_{i}}{n} \text { or } B_{\text {mix }}=\frac{\sum_{i=1}^{n} B_{i}}{n}
$$

242 - the Formulated Hillslope and Bottom $(\mathrm{FoBH})(\mathrm{Eq} .5 \mathrm{c})$ using the formulae of the CA:

$$
\text { (5c) } H_{\text {mix }}=\left(\sum_{i=1}^{n} \frac{p_{i}}{H_{i}}\right)^{-1} \text { or } B_{\text {mix }}=\left(\sum_{i=1}^{n} \frac{p_{i}}{B_{i}}\right)^{-1}
$$


245 Independent action (IA). This method assumes that the effect of each component is an 246 independent event ${ }^{27}$. Thus, the probability to exert a specific effect of the mixture is the joint 247 probability of the effect of each compound applied independently. For calculating the relative 248 response of the mixture, the data for individual compounds were converted into a probability.

An antagonistic effect induced by compound $i$ is obtained by subtracting the measured relative response $\left(\mathrm{R}_{\mathrm{ik}}\right)$ from $100 \%$ (100\% being the relative response of TCDD EC $\left.\mathrm{C}_{50}\right)$ and then converted 252 into a probability (scale $0-1$, by dividing by 100$)$. The relative response of the mixture $(0 \%-100 \%)$ 253 is calculated from the combination of individual probabilities of each compound using the adapted 254 formula (Eq. 6) $)^{28,29:}$

$$
\text { (6) } R_{m i x, k}=1-\left(1-\prod_{i=1}^{n}\left(1-\frac{100-R_{i k}}{100}\right)\right)
$$

256 At a specific concentration $k, R_{\text {mix,k }}$ is the relative response of the mixture; $R_{i k}$ is the relative 257 response of compound $i$ at that concentration $k$ of the mixture, $n$ is the number of the active 258 components.

260 Generalized concentration addition (GCA). GCA (Eq. 7) assumes that the hillslope for each 261 component is equal to 1 and considers also their $\mathrm{RPC}_{\mathrm{Max}}{ }^{31}$. It was adapted for AhR antagonistic 262 activity similarly to the IA model by assuming $100 \%$ as no effect:

$$
\text { (7) } R_{m i x, k}=100-\frac{\sum_{i=1}^{n} \frac{R P C_{M a x, i} C_{i k}}{I C_{50 i}}}{1+\sum_{i=1}^{n} \frac{C_{i k}}{I C_{50 i}}}
$$

264 where $R_{\text {mix,k }}$ is the relative response of the mixture at a specific concentration $k, C_{i k}$ is the 265 concentration of compound $i$ in the mixture at that specific mixture concentration $k$. $R P C_{\text {Max, }}$ is the maximum effect of compound $i$ and $I C_{50 i}$ is the $I C_{50}$ of compound $i$. 


\section{Results}

268 In DR-H4IIE cells, while $\alpha$-chlordane caused cytotoxicity at the highest tested concentration of 80 $269 \mu \mathrm{M}, t$-nonachlor already did at $62.5 \mu \mathrm{M}$ in three cytotoxicity tests (data not shown). They were 270 also cytotoxic for the DR-T47-D at lower concentrations of 30 and $30.5 \mu \mathrm{M}$, respectively. These 271 cytotoxic concentrations were excluded from the data analyses. None of the other compounds or 272 mixtures induced cytotoxicity at any tested concentration.

\subsection{Aryl hydrocarbon receptor activities of the 29 POPs}

AhR - mediated agonistic activities. Only four out of the 29 tested POPs presented AhR agonistic activities (RPC $\operatorname{Max} \geq 10 \%$ ). BDE-153, PCB-138, and PCB-118 were active in DR-H4IIE, while BDE-99 was active in DR-T47-D. BDE-99 and BDE-154 were able to trigger a weak agonistic activity $\left(5 \%<\mathrm{RPC}_{\mathrm{Max}}<10 \%\right)$ in DR-H4IIE, as well as $\gamma-\mathrm{HCH}$ in DR-T47-D (Table S2). No agonistic response was recorded in DR-Hep G2 cells for any of the 29 POPs.

AhR - mediated antagonistic activities. Sixteen out of the 29 individually tested POPs displayed AhR antagonisms. No antagonistic activities were observed for any of the PFAAs in all three cell lines. In contrast, in DR-H4IIE cells, AhR antagonistic responses were recorded for 16 POPs including all PCBs, most of the OCPs (except $p, p^{\prime}-\mathrm{DDE}, \alpha-\mathrm{HCH}$ and $\beta-\mathrm{HCH}$ ), and three out of the seven BRFs (BDE-47, BDE-99 and HCBD) (Table 1). PCB-118 and PCB-138 displayed a

286 V-shaped dose-response curve, switching from antagonistic to agonist behavior at concentrations above $3.5 \mu \mathrm{M}$ and $27.5 \mu \mathrm{M}$, respectively. Hence, their $\mathrm{IC}_{50}$ values were determined by only the antagonistic part of the curve. The dose-response curves obtained from DR-H4IIE cells coexposed to TCDD EC 50 and the 16 AhR antagonistic POPs are shown in Figure S1 (solid lines) with a detail in Table S3. 
291 DR-Hep G2 cells were less responsive to the POPs than DR-H4IIE, with only five compounds 292 exerting antagonistic activities, namely PCB-28, PCB-118, PCB-138, HCB and BDE-47 (Table 1). 293 PCB-28 was the most potent compound, almost completely abolishing the activity of $650 \mathrm{pM}$ 294 TCDD in DR-Hep G2, displaying an $\mathrm{RPC}_{\mathrm{Max}}$ of $7.2 \pm 3.6 \%$ and an $\mathrm{IC}_{50}$ of $6.1 \pm 1.4 \mu \mathrm{M}$. In DR295 T47-D cells, seven out of the 29 POPs showed AhR antagonistic activities (PCB-28, PCB-118, 296 PCB-138, HCB, $\alpha$-chlordane, $t$-nonachlor and $\gamma-\mathrm{HCH})$. The highest potencies were found for $\alpha$ 297 chlordane and $t$-nonachlor with $\mathrm{RPC}_{\operatorname{Max}}$ of $7.4 \pm 12.5 \%$ and $27.8 \pm 3.5 \%$, respectively.

Evaluating competitive inhibition of 16 antagonists in DR-H4IIE. The AhR antagonistic activities were abolished for all compounds (except $\alpha$-chlordane and $t$-nonachlor with $\mathrm{RPC}_{\mathrm{Max}}$ of $56.6 \%$ and $56.8 \%$, respectively) when co-exposing with excessive $20 \mathrm{nM}$ TCDD, indicating they are possible AhR competitive antagonists (Figure S1, dashed lines).

\subsection{Aryl hydrocarbon receptor activities of the POP mixtures}

AhR - mediated agonistic activities. Exposure to the total POP mixture or to the six submixtures described in Table S1 did not induce any significant $\left(\mathrm{RPC}_{\mathrm{Max}} \geq 10 \%\right) \mathrm{AhR}$ agonistic response in any of the cell lines (data not shown), as it could be expected with the exclusion of dl-PCBs and PCDD/F.

AhR - mediated antagonistic activities. The total POP mixture triggered an AhR antagonistic

311 response in all cell lines (Table 2, Figure 1A). At a concentration in the culture medium 312 corresponding to the blood level, the total POP mixture did not interfere with the response of the 313 cells to $\mathrm{EC}_{50} \mathrm{TCDD}$. In contrast, significant and dose-dependent antagonistic responses were 314 already observed at concentrations of 125,250 and 500 fold blood levels, respectively, for DR315 H4IIE, DR-T47-D and DR-Hep G2, although the concentrations of all 29 compounds were below 
316 their respective LOEC at these levels or even at 1000 fold blood levels (Table S1). In DR-H4IIE,

317 the POP mixture displayed a significantly high AhR antagonistic efficacy of $52.5 \pm 2.1 \%$ at 1000

318 fold blood levels and an $\mathrm{IC}_{50}=374 \pm 52$ fold blood levels, while in both human cell lines, a 319 significant response was observed, but did not reach below $80 \%$, making the calculation of an $320 \quad \mathrm{IC}_{50}$ not possible.

322 In parallel, six complementary sub-mixtures (PFAA, $\mathrm{Br}, \mathrm{Cl}, \mathrm{Cl}+\mathrm{Br}, \mathrm{Cl}+\mathrm{PFAA}, \mathrm{Br}+\mathrm{PFAA}$ ) were also 323 tested to study the possible interactions between these groups of compounds. Antagonism was 324 seen for all $\mathrm{Cl}$ containing mixtures (the total $\mathrm{POP}, \mathrm{Cl}, \mathrm{Cl}+\mathrm{Br}$ and $\mathrm{Cl}+\mathrm{PFAA}$ mixtures) in DR-H4IIE 325 and DR-Hep G2, while only the total POP and Cl+PFAA mixtures showed responses in DR-T47326 D (Table 2).

328 In DR-H4IIE cells, the three Cl containing sub-mixtures and the total POP mixture gave more or 329 less similar responses with $I C_{50} \cong 400$ to 500 fold blood levels and $\mathrm{RPC}_{\mathrm{Max}} \cong 50 \%$. This indicates 330 that the chlorinated compounds were responsible for the antagonism of all mixtures where they 331 are present. Also, the antagonistic response curve of Cl+PFAA mixture overlapped that of the 332 total POP mixture, which placed below those of the $\mathrm{Cl}$ and $\mathrm{Cl}+\mathrm{Br}$ (Figure 1B). These observations 333 suggest that the effect of the $\mathrm{Cl}$ mixture was somehow enhanced in the Cl+PFAA mixture, 334 resulting in a dose-response curve overlapping that of the total POP mixture.

3.3. Predictions of the rat aryl hydrocarbon receptor antagonistic activities of the total POP

338 We evaluated the capacity of the three different mathematical models (concentration addition 339 (CA), independent action (IA), and generalized concentration addition (GCA)) to predict the $\mathrm{IC}_{50}$ 340 and dose-response curves of the total POP mixture in the most sensitive cell line, the DR-H4IIE. 
342 Calculation of bottom and hillslope values. Because the 16 rat AhR antagonists contributed 343 only $4.3 \%$ for the mass of the total POP mixture, along with considering all of the 29 POPs to 344 calculating $\mathrm{p}_{\mathrm{i}}$, we also considered only the active compounds, subtracting the weight of the non345 active compounds (sNA) as mentioned in section 2.2.3. WMBH method was unable to predict 346 both bottom and hillslope values. AvBH and FoBH showed reasonable predicted values, 347 especially $\mathrm{AvBH}$ and sNA FoBH for the total POP mixture and the three $\mathrm{Cl}$ containing sub348 mixtures (Table S4).

Prediction of mixture effects of the three models. The results obtained after running the three models are shown in Figure 2. While the IA predicted a really strong response even at the lowest concentrations of the mixture, far out of the range of the measured curve, both the CA (CA-AvBH and CA-sNA FoBH) and GCA predictions resulted in calculated curves comparable to the measured curve. This refers that the 16 active compounds in the total POP mixture acted additively rather than independently.

The measured $\mathrm{IC}_{50}$ of the total POP mixture ( $374 \pm 52$ fold blood levels) was lower than the predicted value (784 fold blood levels for both the GCA and CA models), while the IA model predicted $\mathrm{IC}_{50}=2153$ fold blood levels. Thus, both CA and GCA models underestimated $\mathrm{IC}_{50}$ of the total POP mixture by about two folds, much less than one order of magnitude.

Concerning the calculated dose-response curves, the two additive models appeared to diverge: GCA produced a somewhat better prediction in the low concentration range, both $\mathrm{CA}$ (CA-AvBH and $\mathrm{CA}$-sNA FoBH) closely followed the experimental curve and only diverged at concentrations 365 higher than around 1000 fold blood levels (Figure 2). Similar predictions were also shown for the three active $\mathrm{Cl}, \mathrm{Cl}+\mathrm{Br}, \mathrm{Cl}+\mathrm{PFAA}$ sub-mixtures (Table S4, Figure S2). 
Toxic units. Derived from CA model, toxic units (i.e. the ratio of the concentration partition of a compound to its $\left.I C_{50}\left(p_{i} / I C_{50, i}\right)\right)$ scales the concentrations of the mixture components to its toxicity, represented by the transcriptional activity of the Cyp1a1 promotor. Thus, it has been applied to

371 identify the main driver(s) for mixture effects in CA model $24,28,41$. Figure $3 A$ clearly shows that PCB-

372138 and PCB-118 were the two main contributors for the AhR antagonism of the total POP 373 mixture, constituting to $90 \%$ of the total combined activity. Since they were also partial agonists, 374 it is likely that, in the presence of TCDD, they behaved mainly as antagonists especially at low 375 concentrations. Following this prediction, a binary mixture of PCB-138 and PCB-118 was 376 generated according to their concentration in the total POP mixture. The dose-response curve of 377 this mixture followed that of the total POP mixture very closely, with an $\mathrm{IC}_{50}$ of $505 \pm 67$ fold blood levels (while $\mathrm{IC}_{50}=374 \pm 52$ fold blood levels for the total POP mixture) (Figure 3B).

\section{Discussion}

AhR transactivation activities of the 29 POPs and the mixtures. This study shows that a majority of the chemicals composing the realistic total POP mixture are actually AhR antagonists

383 (16 in DR-H4IIE, five in DR-Hep G2 and seven in DR-T47-D cells). As expected, the total POP

384 mixture and the $\mathrm{Cl}$ containing mixtures were also shown to be antagonistic. These activities were AhR-dependent, and seemed to act through competition for the TCDD binding site, except for $t$ nonachlor and $\alpha$-chlordane.

In our study, we tested the AhR transcriptional activity of POPs and POP mixtures using a 389 transcriptional reporter assay, which basically reports the canonical AhR-driven pathways via AhR-ARNT-DRE interactions. However, we observed that two of the compounds ( $\alpha$-chlordane and $t$-nonachlor) do not seem to exert their antagonistic effect through competitive binding to AhR. 
411 Differences between $\mathrm{IC}_{50}$ or $\mathrm{EC}_{50}$ values of this study and those from previous findings ${ }^{44,45}$ may 412 result from differences in the experimental design and the regression methods (i.e. the number of 413 concentration points, availability of a maximum effect if a full curve is generated, extrapolation if 414 the maximum effect is not reached, and the regression function used with either four or three 415 parameters). Our study not only confirms and consolidates previous findings ${ }^{44,45}$, but it also 416 contributes new data including full dose-response curves with four parameter fit (see Table S3) 
417 which can be used for further data treatment or calculation of the joint effect of any mixture made

418 from these 29 POPs for the rat DR-H4IIE cells.

419 We observed species and tissue differences in the AhR transcriptional activities of the individual 420 POPs and of the mixtures. In general, the rat DR-H4IIE cells were more sensitive than the two 421 human cells towards the effects on AhR transactivation when exposed to individual POPs or POP 422 mixtures. Several considerations may explain this result. Interspecies differences in AhR structure 423 will obviously shape the sensitivity. Rats are 1000 folds more sensitive to TCDD than guinea 424 pigs $^{46}$. Mouse AhR has a higher affinity than human AhR due to the different position of the 425 important amino acid Valine (V381 in humans corresponding to V375 in mice) $)^{47}$. Human AhR has 426 shown a higher relative affinity for certain structurally compounds i.e. endogenous ligands or 427 polyphenols ${ }^{48}$. Moreover, the difference in genetic modification (origins of the integrated promotor and DREs) of the rat DR-H4IIE compared to the two human cell lines could also play a role for the specific responses. Differences in regulatory processes downstream of AhR binding may be responsible, such as differential binding to transcriptional coactivators ${ }^{49}$. Finally, in the 431 antagonistic tests, the POPs have to compete with increasing TCDD concentration (15 pM, 150 pM and 650 pM, respectively for DR-H4IIE, DR-T47-D and DR-Hep G2), which could lead to the

433 lower sensitivity to detect an antagonistic activity of the POPs in the two human cells compared 434 to the rat cells.

Mixtures relevant for human exposure antagonize AhR activation. The most striking result of 437 this study is that the total mixture of 29 POPs, derived from concentrations found in the blood of 438 a Scandinavian population, and sub-mixtures thereof were found to exert only antagonistic effects 439 on AhR. This observation is consistent with our results obtained from testing each compound 440 alone, revealing a majority of antagonistic compounds. AhR antagonism of POPs has been 441 observed in several screening studies ${ }^{44,45}$ and mixture studies ${ }^{50,51}$. However, while the AhR 442 agonistic activity of POPs has been studied for decades, the antagonistic counterpart has not yet 
443 received much attention, especially regarding its physiological consequences on an organism's 444 health.

445 This finding challenges the method of using toxic equivalency factors (TEFs) and toxic equivalent 446 quantities (TEQ) for risk assessments of mixtures of AhR ligands. The World Health Organization 447 assigned TEFs for PCDDs/PCDFs/dl-PCBs, expressed as relative effect potencies compared to 448 the most toxic form TCDD. Regarding their additive mechanism, TEFs are also used to estimate 449 TEQ for a mixture of compounds by adding up the TEF fraction and the concentration of each 450 compound within the mixture ${ }^{52}$. However, PCB mixtures alone or in combination with 451 PCDDs/PCDFs (usually TCDD) have shown additive but also non-additive responses ${ }^{53,54}$. Also, 452 several environmentally abundant biphenyls antagonize the cyp1a1 induction by TCDD ${ }^{12}$, while 453 some dl-mono-ortho-substituted PCBs revealed both agonistic and antagonistic properties ${ }^{55,56}$. In 454 many environmental samples, the ratio between PCBs and AhR agonists is above 1000, 455 indicating that antagonisms, resulting from interactions between AhR agonists and PCBs ${ }^{57}$, are 456 not irrelevant. Therefore, the antagonistic effect of these compounds should be also considered 457 to calculate the effect of mixtures. Since they are more abundant in real-life mixtures, their 458 antagonisms may undermine or even abolish the overall dioxin potency of the environmental 459 mixtures ${ }^{12}$.

461 Our finding also raises the issue of the biological significance of a predominantly AhR antagonistic 462 mixture in the blood of a human population. We found antagonistic activities at levels of 125 fold 463 blood levels in rat liver cells or 250 or 500 folds in human mammary gland and liver cells, levels 464 that may realistically be reached after an accident or in exposed populations.

466 It is important to note that in the total POP mixture used here ${ }^{36}$, no dioxins and dl-compounds 467 were included. That allows us to study the antagonism of the human-exposure relevant POP 468 mixtures by isolating them from the dioxin and dl-compounds. But the roles of the dioxin and dl- 
compounds in human exposure should have also been considered. Therefore, we attempted to estimate the effect of the total POP mixture in a real-life situation. According to Kvalem et al. ${ }^{58}$, the median of dl-compounds in Norwegian human blood was $33.1 \mathrm{pg} T E Q / \mathrm{g}$ lipid, which is equal to $0.6 \mathrm{pM}$ in blood assuming that blood contains $0.6 \%$ fat and $1 \mathrm{ml}$ blood $=1 \mathrm{~g}$. Thus, the respective LOECs (for the POP mixture AhR antagonistic activity) in DR-H4IIE, DR-T47-D and DR-Hep G2 of 125, 250, and 500 fold human blood level correspond to 75 pM, 150 pM and 300 $\mathrm{pM}$ of dl-compounds, respectively. This concentration is close to the TCDD EC 50 (15 pM TCDD in DR-H4IIE, 150 pM in DR-T47-D and 650 pM in DR-Hep G2 cells) used in our antagonistic assays. Therefore, it is likely that the total POP mixture would antagonize the activity of these dlcompounds in the Scandinavian population.

Furthermore, the question arises whether an overall AhR antagonistic exposure would actually cause health problems by interfering with the normal AhR function. Increasing evidence suggests that endogenous $A h R$ ligands exist ${ }^{59,60}$, complemented by dietary phytochemical-derived AhR agonists/antagonists ${ }^{61,62}$. AhR induced functions are essential for a variety of normal physiological functions. In mammary tissue, AhR likely plays a physiological role in coordinating development, differentiation, cell growth, and signaling of hormones ${ }^{63-67}$. Knock out mice or mice with low affinity AhR variants display impaired survival, growth, fertility, liver function and innate and adaptive immunity $^{68}$. It is thus conceivable that the presence of highly stable POPs may interfere with the essential function of AhR controlled by mostly short-lived endogenous and dietary ligands, and thus impair cellular AhR mediated processes. The risk caused by AhR antagonism as the major effect of POPs could well exceed that due to their agonistic effect, however the health effect associated to AhR antagonism is unclear and deserves further investigation.

Predictions of mixture effects. Risk assessment for mixture exposure is crucial to protect the health of both humans and wildlife. The individual chemical approach underestimates the mixture 
exposure and decreases the accuracy of risk assessment ${ }^{22,23,69}$. In addition, the risk of exposure

496 to multiple chemicals at doses below their threshold, which is the most common case in real-life,

497 should not be underestimated or assumed as no-effect.

In this study, the best prediction results were obtained using the CA (concentration addition) and

GCA (generalized concentration addition) models. They performed well in predicting $\mathrm{IC}_{\mathrm{mix}, 50}=784$

fold blood levels within two folds from the measured value ( 374 fold blood levels). This is considered as well accepted in predicting the combined effect of complex mixtures i.e. the total POP mixture with its components present at low concentration (lower than their LOECs at 1000 fold blood levels) and belonging to different compound groups.

$\mathrm{CA}$ is often chosen as the default model ${ }^{70}$ for predicting mixture activities, first for mixtures with similar compounds ${ }^{24}$ then expended to dissimilar compounds ${ }^{23,25,26}$. Previous studies have shown the capability of the CA model to predict the mixture effect using the information of individual chemicals obtained in vitro $25,41,71,72$, ex vivo ${ }^{73}$ or in vivo ${ }^{23,25}$. In vitro research has mainly focused on an equimolar mixture with less than ten components and at high exposure concentrations.

511 Birkhøj et al. ${ }^{25}$ successfully applied the CA model to predict the antiandrogenic effect of a mixture 512 of five commonly used pesticides at $10 \mu \mathrm{M}$ each. In contrast, the CA model was unable to predict 513 the effect on thyroid hormone function and AhR transactivation of another mixture of five different 514 pesticides at the maximum concentration of $50 \mu \mathrm{M}$ each, due to the presence of an inhibitory compound ${ }^{71}$. Other studies focused on more complex mixtures with multiple components at lower

516 doses, typically below their threshold doses, or on human or environmentally relevant exposure 517 scenarios. Two complex mixtures of 17 estrogenic chemicals were screened for estrogenic 518 activities, reporter-gene (ERLUX) and cell proliferation (ESCREEN) endpoints ${ }^{41}$. This represents 
one of the most comprehensive studies on the effects of mixtures where they were able to predict

520 the effects of the two mixtures.

521 GCA, on the other hand, has been recently developed and proven useful specifically for calculating mixtures containing partial agonists ${ }^{30-32}$, but has not been applied before to calculate the activity of AhR antagonists. It allows to consider theoretically the fact that some agonists never reach the full activity of TCDD, or that some antagonists present partial agonistic activities.

The difference between CA and GCA models resides in the predicted dose-response curve of the mixture and in the maximum predicted activity of the total POP mixture (Figure 2). GCA predicting the mixture response, allows to generate the full dose-response curve of the mixture using only the data from testing the individual compounds (i.e. $\mathrm{RPC}_{\mathrm{Max}}$, concentration and $\mathrm{IC}_{50}$ ). The reason why this predicted curve diverged from the experimental curve at higher concentrations could result from the assumption that the hillslopes of all components, and so of the POP mixture, are equal to 1 , which is clearly not the case (Table S3). However, GCA predicted the bottom (RPC $\operatorname{Max}$ $=52 \%)$ very close to the observed value for the total POP mixture $(52.5 \%)$ thanks to its consideration of the RPC $\operatorname{Max}$.

On the other hand, CA provides a prediction of $\mathrm{IC}_{\mathrm{mix}, \mathrm{j}}$ without the full dose-response curve. Therefore, we calculated the hillslope and the bottom values for the mixture response based on

538 its components by formulating several possibilities. The dose-response curve generated by CA 539 with averaged bottom hillslope $(\mathrm{CA}-\mathrm{AvBH})$ resulted in the best fit with reasonable hillslope and 540 bottom values (1.7 and $21 \%$ ) compared to 1.3 and $52.5 \%$, respectively of the measured POP 541 mixture curve. Subtracted non-activated compounds and formulated bottom hillslope (sNA FoBH)

542 predicted an overlapped curve with the observed up to 1000 fold blood levels because of its closer

$543 \quad H_{\text {mix }}=1.5$, but overestimated the extension of antagonism at higher concentration, leading to the 544 prediction of $B_{\text {mix }}=0 \%$ for the total POP mixture. $B_{\text {mix }}$ is important when predicting the activity of 
545 a mixture for risk assessment. Therefore, $\mathrm{CA}-\mathrm{AvBH}$ rather than $\mathrm{CA}-\mathrm{sNA}$ FoBH was chosen as a

546 more suitable prediction in our case. The CA model also provides a good prediction of $\mathrm{IC}_{\text {mix,50 }}$ for 547 the response of the DR-H4IIE cells to the active sub-mixtures as to the total POP mixture, and 548 reasonable predicted dose-response curves (Table S4, Figure S2).

550 Finally, IA (independent action) was designed specifically for mixtures of compounds with clearly 551 different MOAs to combine probabilities of action of individual compounds. Previous studies 552 showed that IA outperformed $\mathrm{CA}^{23}$ or was comparable to $\mathrm{CA}$ with equal ${ }^{29}$ or not more than five553 fold differences ${ }^{28,74}$ in predicting the combined effects for chemicals having different MOAs. The 554 bad performance of IA to predict either $I C_{\text {mix }}$ or the dose-response curve clearly results from the 555 mixture studied here, where we showed that most components act through the same MOAs. At 556 low doses, accumulation of the individual, low probabilities derived for a high number of individual 557 compounds presumably resulted in the dramatic overestimation of the antagonistic effect.

\section{Conclusions}

560 We tested the AhR agonistic and antagonistic activities of 29 POPs shown to contaminate human 561 blood, both in individual and mixture forms. AhR transactivation activities in three reporter cell

562 lines exposed to the 29 POPs and the mixtures were different due to the species and tissue563 specific responses. The predominant individual activities of the POPs were AhR antagonism, as 564 shown for 16 compounds out of 29 in rat DR-H4IIE cells, and for seven and five compounds in 565 human DR-T47-D and DR-Hep G2, respectively. The total POP mixture already induced a 566 significant AhR antagonistic activity at concentrations of 125,250 , and 500 fold human blood 567 levels, respectively in DR-H4IIE, DR-T47-D and DR-Hep G2, although each individual compound was present at concentrations lower than its LOEC at these levels. Such blood levels of POPs could realistically occur in food or environmental contamination incidents or in highly exposed 570 sub-populations. Chlorinated compounds, among which PCB-118 and PCB-138 contributed 90\% 
571 to the activity of the total POP mixture, were the drivers for AhR antagonism in DR-H4IIE cells.

572 Finally, CA and GCA proved to be good tools to predict the mixed effect of the total POP mixture 573 with only two-fold underestimated $\mathrm{IC}_{50}$ and acceptable does response curves. Hence, the 574 compounds acted additively in the mixtures. Although limitations remain to fully describe the 575 effects of realistic mixtures due to biological complexity, the predictions obtained using CA and 576 GCA seem suitable for establishing general regulatory guidelines for mixture toxicity 577 assessments. In addition, the data generated in this study for individual compounds will be useful 578 to predict the effect of other complex mixtures constituted by these compounds.

580 Conflict of interest: The authors declare that there is no conflict of interest.

581 Acknowledgements: This project has received funding from the European Union's Horizon 2020 582 research and innovation program under the Marie Skłodowska-Curie grant agreement No. 583 722634. Muller M. is "Maître de Recherche" at the "Fonds National de la Recherche Scientifique". 


\section{References}

586 1. Hankinson O. The Aryl Hydrocarbon Receptor Complex. Annu Rev Pharmacol Toxicol.

2. WHO. Consultation on assessment of the health risk of dioxins; re-evaluation of the tolerable daily intake (TDI): Executive Summary. Food Addit Contam. 2000;17(4):223240. doi: $10.1080 / 713810655$

3. Denison MS, Nagy SR. Activation of the aryl hydrocarbon receptor by structurally diverse

5. Gonzalez FJ, Fernandez-Salguero P. The Aryl Hydrocarbon Receptor. Studies Using the AHR-Null Mice. Drug Metab Dispos. 1998;26(12):1194-1198.

6. Harrill JA, Hukkanen RR, Lawson M, et al. Knockout of the aryl hydrocarbon receptor results in distinct hepatic and renal phenotypes in rats and mice. Toxicol Appl Pharmacol. 2013;272(2):503-518. doi:10.1016/j.taap.2013.06.024

7. Lahvis GP, Lindell SL, Thomas RS, et al. Portosystemic shunting and persistent fetal vascular structures in aryl hydrocarbon receptor-deficient mice. Proc Natl Acad Sci. 2000;97:10442-10447. doi:10.1073/pnas.190256997

8. Butler R, Inzunza J, Suzuki H, Fujii-Kuriyama Y, Warner M, Gustafsson JÅ. Uric acid stones in the urinary bladder of aryl hydrocarbon receptor (AhR) knockout mice. Proc Natl Acad Sci U S A. 2012;109(4):1122-1126. doi:10.1073/pnas.1120581109

9. Hahn ME, Karchner SI, Merson RR. Diversity as opportunity: Insights from 600 million years of AHR evolution. Curr Opin Toxicol. 2017;2:58-71. doi:10.1016/j.cotox.2017.02.003 
611 10. Butler RA, Kelley ML, Powell WH, Hahn ME, Van Beneden RJ. An aryl hydrocarbon 612 receptor (AHR) homologue from the soft-shell clam, Mya arenaria: Evidence that 613 invertebrate AHR homologues lack 2,3,7,8-tetrachlorodibenzo-p-dioxin and $\beta$ naphthoflavone binding. Gene. 2001;278(1-2):223-234. doi:10.1016/S03781119(01)00724-7

11. Marlowe JL, Puga A. Aryl hydrocarbon receptor, cell cycle regulation, toxicity, and tumorigenesis. J Cell Biochem. 2005;96(6):1174-1184. doi:10.1002/jcb.20656

12. Wall RJ, Fernandes A, Rose M, Bell DR, Mellor IR. Characterisation of chlorinated, brominated and mixed halogenated dioxins, furans and biphenyls as potent and as partial

13. Murk A, Legler J, Denison M, Giesy J, van de Guchte C, Brouwer A. Chemical-activated luciferase gene expression (CALUX): a novel in vitro bioassay for Ah receptor active

14. Scippo ML, Eppe G, De Pauw E, Maghuin-Rogister G. DR-CALUX® screening of food samples: Evaluation of the quantitative approach to measure dioxin, furans and dioxinlike PCBs. Talanta. 2004;63(5):1193-1202. doi:10.1016/j.talanta.2004.05.037

15. Goeyens L, Hoogenboom R, Eppe G, et al. Discrepancies between Bio-analytical and Chemo-analytical results have a non-negligible message. Organohalogen Compd. 2010;72:964-967.

16. Vizcaino E, Grimalt JO, Fernández-Somoano A, Tardon A. Transport of persistent organic pollutants across the human placenta. Environ Int. 2014;65:107-115.

634 17. Stockholm Convention. Stockholm Convention on Persistent Organic Pollutants. Vol 9.; 1997.

636 18. Bopp SK, Barouki R, Brack W, et al. Current EU research activities on combined 
exposure to multiple chemicals. Environ Int. 2018;120:544-562. doi:10.1016/j.envint.2018.07.037

19. Kortenkamp A. Ten years of mixing cocktails: A review of combination effects of endocrine-disrupting chemicals. Environ Health Perspect. 2007;115(Suppl 1):98-105.

20. EC COM. Communication from the Commission on Combination Effects of Chemicals (Chemical Mixtures).; 2012.

21. Berenbaum MC. What is synergy? Pharmacol Rev. 1985;41(2):93-141.

22. Kortenkamp A, Backhaus T, Faust M. State of the Art Report on Mixture Toxicity. Report to the Commission of the European Union (Directorate General for the Environmen).;

23. Thrupp TJ, Runnalls TJ, Scholze M, Kugathas S, Kortenkamp A, Sumpter JP. The consequences of exposure to mixtures of chemicals: Something from 'nothing' and 'a lot from a little' when fish are exposed to steroid hormones. Sci Total Environ. 2018;619620:1482-1492. doi:10.1016/j.scitotenv.2017.11.081

24. Loewe S, Muischnek H. Combinated effects I Announcement-Implements to the problem. Naunyn Schmiedebergs Arch Exp Pathol Pharmakol. 1926;114:313-326.

25. Birkhøj M, Nellemann C, Jarfelt K, et al. The combined antiandrogenic effects of five commonly used pesticides. Toxicol Appl Pharmacol. 2004;201(1):10-20. doi:10.1016/j.taap.2004.04.016

26. Orton F, Ermler S, Kugathas S, Rosivatz E, Scholze M, Kortenkamp A. Mixture effects at very low doses with combinations of anti-androgenic pesticides, antioxidants, industrial pollutant and chemicals used in personal care products. Toxicol Appl Pharmacol. 2014;278(3):201-208. doi:10.1016/j.taap.2013.09.008

27. Bliss Cl. The Toxicity of Poisons Applied Jointly. Ann Appl Biol. 1939;26(3):585-615. doi:10.1111/j.1744-7348.1939.tb06990.x 
663

664

665

666

667

668

669

670

671

672

673

674

675

676

677

678

679

680

681

682

683

684

685

686

687

688

28. Backhaus $\mathrm{T}$, Arrhenius $\AA$, Blanck $\mathrm{H}$. Toxicity of a mixture of dissimilarly acting substances to natural algal communities: predictive power and limitations of independent action and concentration addition. Environ Sci Technol. 2004;38(23):6363-6370.

doi:org/10.1021/es0497678

29. Payne J, Rajapakse N, Wilkins M, Kortenkamp A. Prediction and assessment of the effects of mixtures of four xenoestrogens. Environ Health Perspect. 2000;108(10):983987. doi:10.1289/ehp.00108983

30. Howard GJ, Webster TF. Generalized concentration addition: a method for examining mixtures containing partial agonists. J Theor Biol. 2009;259(3):469-477. doi:10.1016/j.jtbi.2009.03.030

31. Howard GJ, Schlezinger JJ, Hahn ME, Webster TF. Generalized Concentration Addition Predicts Joint Effects of Aryl Hydrocarbon Receptor Agonists with Partial Agonists and Competitive Antagonists. Env Heal Perspect. 2010;118(5):666-672. doi:10.1289/ehp.0901312

32. Brinkmann M, Hecker M, Giesy JP, et al. Generalized concentration addition accurately predicts estrogenic potentials of mixtures and environmental samples containing partial agonists. Toxico/ Vitr. 2018;46(June 2017):294-303. doi:10.1016/j.tiv.2017.10.022

33. Småstuen L, Salihovic S, Ericson I, et al. Levels in food and beverages and daily intake of perfluorinated compounds in Norway. 2010;80:1137-1143. doi:10.1016/j.chemosphere.2010.06.023

34. Knutsen HK, Kvalem HE, Thomsen C, et al. Dietary exposure to brominated flame retardants correlates with male blood levels in a selected group of Norwegians with a wide range of seafood consumption. Mol Nutr Food Res. 2008;52(2):217-227. doi:10.1002/mnfr.200700096

35. Polder A, Thomsen C, Lindström G, Løken KB, Skaare JU. Levels and temporal trends of chlorinated pesticides, polychlorinated biphenyls and brominated flame retardants in 
individual human breast milk samples from Northern and Southern Norway. Chemosphere. 2008;73(1):14-23. doi:10.1016/j.chemosphere.2008.06.002

36. Berntsen HF, Berg V, Thomsen C, Ropstad E, Zimmer KE. The design of an environmentally relevant mixture of persistent organic pollutants for use in in vivo and in vitro studies. J Toxicol Environ Heal Part A. 2017;24(3):1002-1016. doi:10.1080/15287394.2017.1354439

37. Van der Heiden E, Bechoux N, Muller M, et al. Food flavonoid aryl hydrocarbon receptormediated agonistic/antagonistic/synergic activities in human and rat reporter gene assays. Anal Chim Acta. 2009;637(1-2):337-345. doi:10.1016/j.aca.2008.09.054

38. Garrison PM, Tullis K, Aarts JMMJG, Brouwer A, Giesy JP, Denison MS. SpeciesSpecific Recombinant Cell Lines as Bioassay Systems for the Detection of 2,3,7,8Tetrachlorodibenzo- p -dioxin-like Chemicals. Toxicol Sci. 1996;30(2):194-203. doi:10.1093/toxsci/30.2.194

39. Scippo M, Rybertt MS, Focant J, et al. Evaluation of the DR-CALUX screening of food and feed, according to regulation levels including DL-PCB. Organohalogen Compd. 2005;67:1397-1402.

40. OECD. Test No. 455: Performance-Based Test Guideline for Stably Transfected Transactivation In Vitro Assays to Detect Estrogen Receptor Agonists and Antagonists. 2016. doi: $10.1787 / 20745788$

41. Evans RM, Scholze M, Kortenkamp A. Additive mixture effects of estrogenic chemicals in human cell-based assays can be influenced by inclusion of chemicals with differing effect profiles. PLoS One. 2012;7(8). doi:10.1371/journal.pone.0043606

42. Wright EJ, Pereira De Castro K, Joshi AD, Elferink CJ. Canonical and non-canonical aryl hydrocarbon receptor signaling pathways. Curr Opin Toxicol. 2017;2:87-92. doi:10.1016/j.cotox.2017.01.001

43. Jaeger C, Tischkau SA. Role of Aryl Hydrocarbon Receptor in Circadian Clock Disruption 
and Metabolic Dysfunction. 2016;(Dim):133-141. doi:10.4137/EHI.S38343.TYPE

44. Brenerová $\mathrm{P}$, Hamers $\mathrm{T}$, Kamstra JH, et al. Pure non-dioxin-like PCB congeners suppress induction of AhR-dependent endpoints in rat liver cells. Environ Sci Pollut Res.

46. Hulme EC, Trevethick MA. Ligand binding assays at equilibrium: Validation and

47. Ramadoss P, Perdew GH. Use of 2-Azido-3-[125 I] iodo-7,8-dibromodibenzo-p-dioxin as

49. Flaveny C, Reen RK, Kusnadi A, Perdew GH. The mouse and human Ah receptor differ in recognition of LXXLL motifs. Arch Biochem Biophys. 2008;471(2):215-223.

48. Flaveny CA, Murray IA, Chiaro CR, Perdew GH. Ligand Selectivity and Gene Regulation by the Human Aryl Hydrocarbon Receptor in Transgenic Mice. 2009;75(6):1412-1420. doi:10.1124/mol.109.054825 doi:10.1016/j.abb.2008.01.014

50. Harper N, Connor K, Steinberg M, Safe S. Immunosuppressive activity of polychlorinated biphenyl mixtures and congeners: nonadditive (antagonistic) interactions. Fundam Appl Toxicol. 1995;27(1):131-139.

51. Long M, Deutch B, Bonefeld-Jorgensen EC. AhR transcriptional activity in serum of Inuits across Greenlandic districts. Environ Heal A Glob Access Sci Source. 2007;6(32). doi:10.1186/1476-069X-6-32 
52. Van den Berg M, Birnbaum LS, Denison M, et al. The 2005 World Health Organization reevaluation of human and mammalian toxic equivalency factors for dioxins and dioxinlike compounds. Toxicol Sci. 2006;93(2):223-241. doi:10.1093/toxsci/kfl055

53. Safe SH. Development validation and problems with the toxic equivalency factor

54. Safe S. Limitations of the toxic equivalency factor approach for risk assessment of TCDD

55. Clemons JH, Myers CR, Lee LEJ, Dixon DG, Bols NC. Induction of cytochrome P4501A by binary mixtures of polychlorinated biphenyls (PCBs) and 2,3,7,8-tetrachlorodibenzo-pdioxin (TCDD) in liver cell lines from rat and trout. Aquat Toxicol. 1998;43(2-3):179-194. doi:10.1016/0166-445X(93)90030-5

56. Hestermann E V., Stegeman JJ, Hahn ME. Relative contributions of affinity and intrinsic efficacy to aryl hydrocarbon receptor ligand potency. Toxicol Appl Pharmacol. 2000;168(2):160-172. doi:10.1006/taap.2000.9026

57. Fiedler H. The Handbook of Environmental Chemistry. Persistent Organic Pollutants. Vol 3. Springer, Berlin; 2003.

58. Kvalem HE, Knutsen HK, Thomsen C, et al. Role of dietary patterns for dioxin and PCB exposure. Mol Nutr Food Res. 2009;53(11):1438-1451. doi:10.1002/mnfr.200800462

59. Rannug A, Rannug U, Rosenkranz H, et al. Certain photooxidized derivatives of tryptophan bind with very high affinity to the Ah receptor and are likely to be endogenous signal substances. J Biol Chem. 1987;262(32):15-427.

60. Rannug A, Rannug U. The tryptophan derivative 6-formylindolo [3,2-b] carbazole, FICZ, a dynamic mediator of endogenous aryl hydrocarbon receptor signaling, balances cell growth and differentiation. Crit Rev Toxicol. 2018;48(7):555-574. 
doi:10.1080/10408444.2018.1493086

61. Powell JB, Ghotbaddini M. Cancer-promoting and Inhibiting Effects of Dietary Compounds: Role of the Aryl Hydrocarbon Receptor (AhR). Biochem Pharmacol. 2014;3(1):1-21. doi:10.4172/2167-0501.1000131

62. Jin UH, Park H, Li X, et al. Structure-Dependent Modulation of Aryl Hydrocarbon Receptor-Mediated Activities by Flavonoids. Toxicol Sci. 2018;164(1):205-217.

63. Hubbard TD, Murray IA, Nichols RG, et al. Dietary Broccoli Impacts Microbial Community

64. Quintana FJ, Basso AS, Iglesias AH, et al. Control of Treg and TH17 cell differentiation by the aryl hydrocarbon receptor. Nature. 2008;453(7191):65-71. doi:10.1038/nature06880

65. Roman ÁC, Carvajal-Gonzalez JM, Merino JM, Mulero-Navarro S, Fernández-Salguero PM. The aryl hydrocarbon receptor in the crossroad of signalling networks with therapeutic value. Pharmacol Ther. 2018;185(xxxx):50-63. doi:10.1016/j.pharmthera.2017.12.003

66. Casado FL. The Aryl Hydrocarbon Receptor Relays Metabolic Signals to Promote Cellular Regeneration. Stem Cells Int. 2016;2016(1):1-9. doi:10.1155/2016/4389802

67. Hushka LJ, Williams JS, Greenlee WF. Characterization of 2,3,7,8Tetrachlorodibenzofuran-Dependent Suppression and AH Receptor Pathway Gene Expression in the Developing Mouse Mammary Gland. Toxicol Appl Pharmacol. 1998;152(1):200-210. doi:10.1006/TAAP.1998.8508

68. Larigot L, Juricek L, Dairou J, Coumoul X. AhR signaling pathways and regulatory functions. Biochim Open. 2018;7:1-9. doi:10.1016/j.biopen.2018.05.001

69. Silva E, Rajapakse N, Kortenkamp A. Something from "nothing" - Eight weak estrogenic 
chemicals combined at concentrations below NOECs produce significant mixture effects. Environ Sci Technol. 2002;36(8):1751-1756. doi:10.1021/es0101227

70. Hardy A, Benford D, Halldorsson T, et al. Draft guidance on harmonised methodologies for human health, animal health and ecological risk assessment of combined exposure to multiple chemicals. EFSA Scientific Committee. EFSA 48 J 201X. 2018:1-81. doi:10.2903/j.efsa.201X.XXXX

71. Ghisari M, Long M, Tabbo A, Bonefeld-Jørgensen EC. Effects of currently used pesticides and their mixtures on the function of thyroid hormone and aryl hydrocarbon receptor in cell culture. Toxicol Appl Pharmacol. 2015;284(3):292-303.

72. Liu L, Liu S-S, Yu M, Zhang J, Chen F. Concentration addition prediction for a multiplecomponent mixture containing no effect chemicals. Anal Methods. 2015;7(23):9912-9917. doi:10.1039/C5AY01784J

73. Gaudriault $\mathrm{P}$, Mazaud-Guittot S, Lavoué V, et al. Endocrine Disruption in Human Fetal Testis Explants by Individual and Combined Exposures to Selected Pharmaceuticals, Pesticides, and Environmental Pollutants. Environ Health Perspect. 2017;125(8):087004. doi:10.1289/EHP1014

74. Faust $\mathrm{M}$, Altenburger $\mathrm{R}$, Backhaus $\mathrm{T}$, et al. Joint algal toxicity of 16 dissimilarly acting chemicals is predictable by the concept of independent action. Aquat Toxicol. 
815 Figure Captions

816 Figure 1: (A) Dose-response curves obtained from DR-H4IIE, DR-T47-D and DR-HepG2 cells 817 co-exposed to $15 \mathrm{pM}, 150 \mathrm{pM}$ and $650 \mathrm{pM}$ TCDD, respectively, and the total POP mixture. (B) 818 Dose-response curves obtained from DR-H4IIE cells co-exposed to 15 pM TCDD, and the total 819 POP mixture, or the $\mathrm{Cl}, \mathrm{Cl}+\mathrm{Br}$ and $\mathrm{Cl}+\mathrm{PFAA}$ sub-mixtures (Mean $\pm \mathrm{SD}, \mathrm{n}=3,0.4 \% \mathrm{DMSO}$ ).

821 Figure 2: Measured and predicted dose-response curves obtained from rat DR-H4IIE cells coexposed to $15 \mathrm{pM}$ TCDD and the total POP mixture, and from three prediction models. $\mathrm{CA}=$

823 Concentration addition, $\mathrm{IA}=$ Independent action, $\mathrm{GCA}=$ Generalized concentration addition,

$824 \mathrm{AvBH}=$ averaged hillslope and bottom, and sNA FoBH = subtracted nonactive compounds,

825 formulated hillslope and bottom. Green dashed lines represent the $95 \%$ confidence interval of the 826 measured response.

827

828 Figure 3: (A) Distribution of toxic units of the 16 active AhR antagonists. (B) Dose-response 829 curves obtained from rat DR-H4IIE cells co-exposed to $15 \mathrm{pM}$ TCDD and the total POP mixture 830 or a binary mixture consisting of PCB-138 and PCB-118 (Mean \pm SD, $n=3,0.4 \%$ DMSO). 
(A)

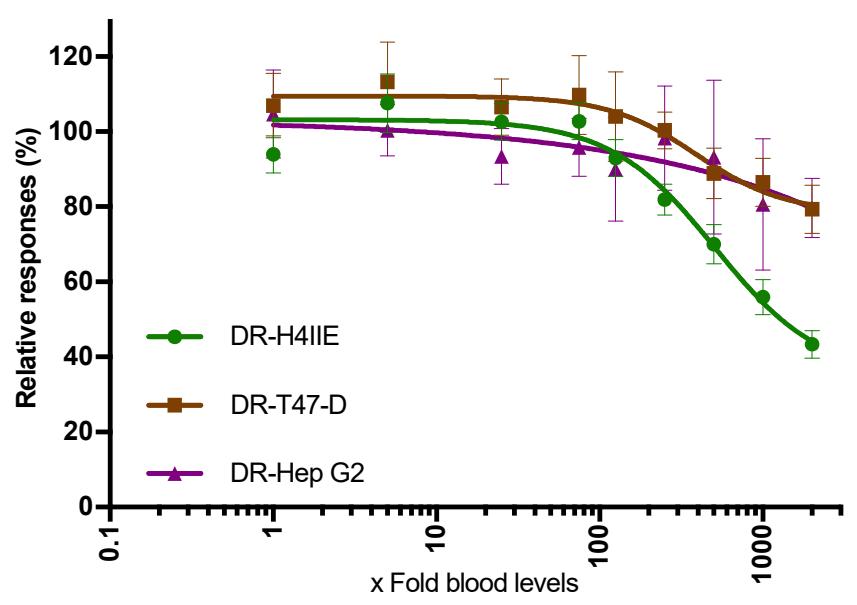

(B)

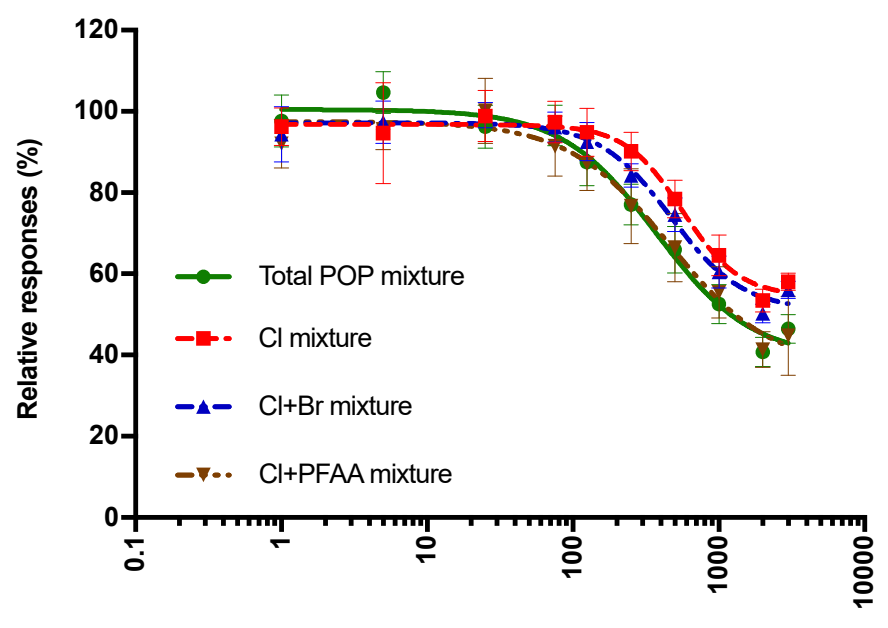

833

$x$ Fold blood levels

Figure 1. 


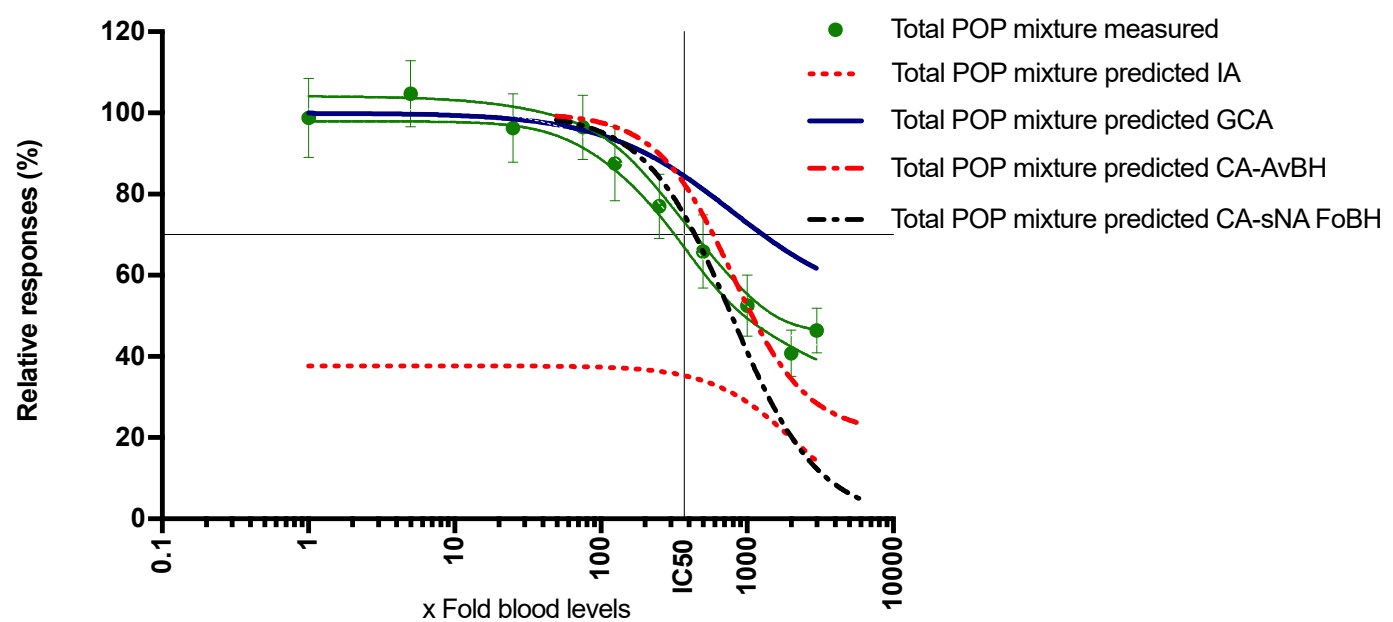

Figure 2. 
(A)

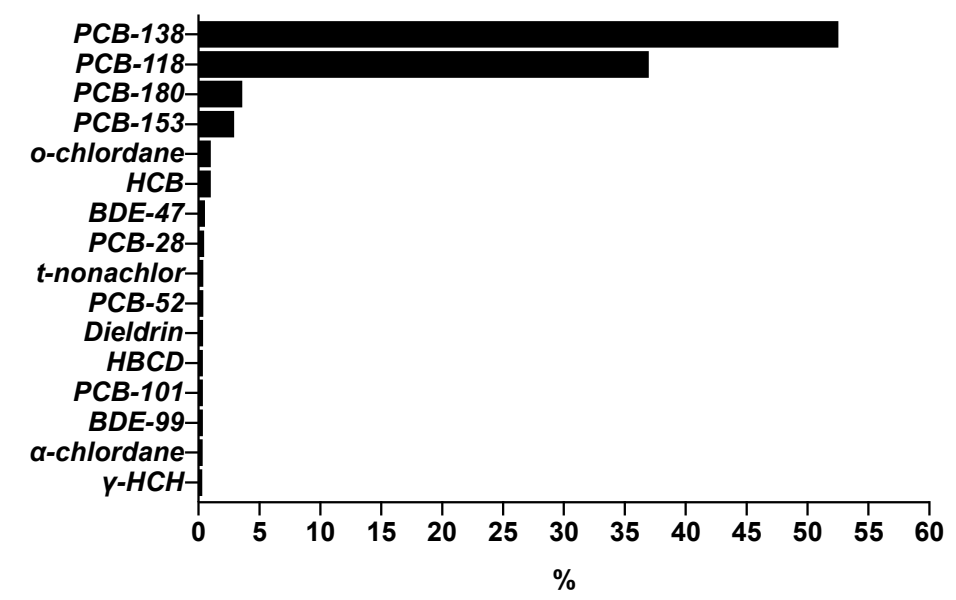

(B)

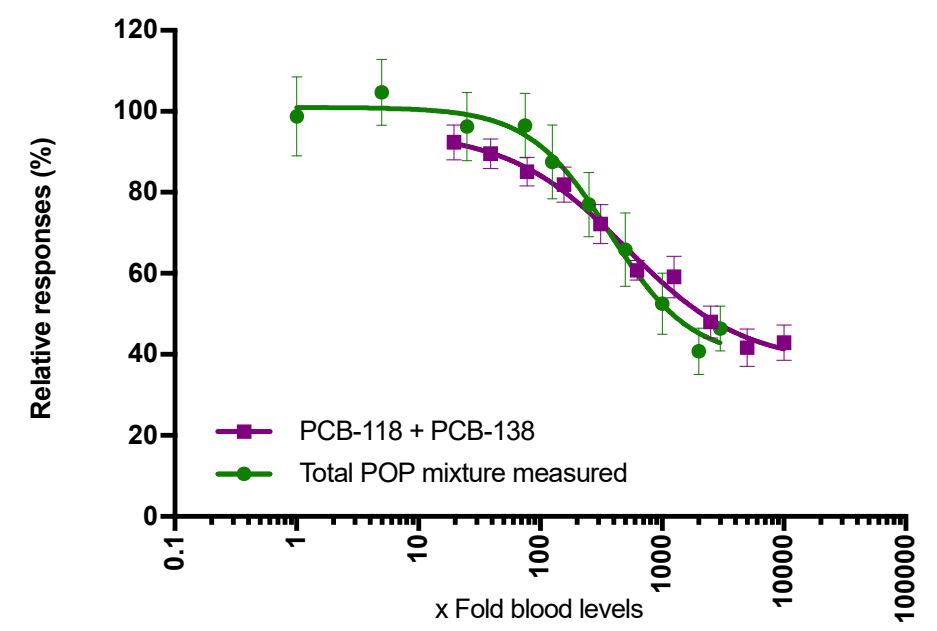

Figure 3. 


\section{Table Captions}

841 Table 1: AhR antagonistic responses (LOEC, MOEC, IC 50 and $\mathrm{RPC}_{\mathrm{Max}}$ ) of 16 POPs in DR-H4IIE, 842 DR-Hep G2 and DR-T47-D cell lines ( $n=3,0.3 \%$ DMSO).

843

844 Table 2: AhR antagonistic responses (LOEC, MOEC, IC $\mathrm{C}_{50}$ and $\mathrm{RPC}_{\mathrm{Max}}$ ) of the total POP mixture 845 and $\mathrm{Cl}$ containing sub-mixtures ( $\mathrm{Cl}, \mathrm{Cl}+\mathrm{Br}, \mathrm{Cl}+\mathrm{PFAA})$ in DR-H4IIE, DR-T47-D and DR-Hep G2 846 cells $(n=3,0.4 \%$ DMSO).

847 
Table 1.

\begin{tabular}{|c|c|c|c|c|c|c|c|c|c|c|c|c|}
\hline \multirow[t]{2}{*}{ Compounds } & \multicolumn{4}{|c|}{ DR-H4IIE } & \multicolumn{4}{|c|}{ DR-Hep G2 } & \multicolumn{4}{|c|}{ DR-T47-D } \\
\hline & $\begin{array}{c}\text { LOEC } \\
(\mu \mathrm{M})\end{array}$ & $\begin{array}{c}\text { MOEC } \\
(\mu \mathrm{M})\end{array}$ & $\begin{array}{c}\mathrm{IC}_{50} \pm \mathrm{SE} \\
(\mu \mathrm{M})\end{array}$ & $\begin{array}{c}\mathrm{RPC}_{\operatorname{Max}} \\
(\%)\end{array}$ & $\begin{array}{c}\text { LOEC } \\
(\mu \mathrm{M})\end{array}$ & $\begin{array}{c}\text { MOEC } \\
(\mu \mathrm{M})\end{array}$ & $\begin{array}{c}\mathrm{IC}_{50} \pm \mathrm{SE} \\
(\mu \mathrm{M})\end{array}$ & $\begin{array}{c}\mathrm{RPC}_{\mathrm{Max}} \\
(\%)\end{array}$ & $\begin{array}{c}\text { LOEC } \\
(\mu \mathrm{M})\end{array}$ & $\begin{array}{c}\text { MOEC } \\
(\mu \mathrm{M})\end{array}$ & $\begin{array}{c}\mathrm{IC}_{50} \pm \mathrm{SE} \\
(\mu \mathrm{M})\end{array}$ & $\mathrm{RPC}_{\operatorname{Max}}(\%)$ \\
\hline PCB-28 & 2.5 & 25 & $6.8 \pm 1.7$ & $36.6 \pm 4.3$ & 2.5 & 25 & $6.1 \pm 1.4$ & $7.2 \pm 3.6$ & 3.5 & 25 & $11.4 \pm 1.5$ & $48.3 \pm 5.9$ \\
\hline PCB-52 & 2.5 & $50^{*}$ & $7.3 \pm 1.2$ & $17.1 \pm 5.5$ & - & - & - & - & - & - & - & - \\
\hline PCB-101 & 12.5 & $50^{*}$ & $17.9 \pm 3.8$ & $54.3 \pm 3.6$ & - & - & - & - & - & - & - & - \\
\hline PCB-118 & 0.5 & 2.5 & $0.3 \pm 0.05$ & $67 \pm 4.7$ & 12.5 & 25 & $9 \pm 2.7$ & $38.3 \pm 16.5$ & 12.5 & 27.5 & $13.6 \pm 2.4$ & $49.2 \pm 4.9$ \\
\hline PCB-138 & 0.5 & 2.5 & $0.6 \pm 0.07$ & $42.8 \pm 2.8$ & 3.5 & 25 & ND & $50.2 \pm 9.5$ & 12.5 & $50^{*}$ & ND & $42.6 \pm 2.5$ \\
\hline PCB-153 & 0.01 & $50^{*}$ & $18.5 \pm 2.8$ & $16.7 \pm 4.6$ & - & - & - & - & - & - & - & - \\
\hline PCB-180 & 1 & $50^{*}$ & $7.4 \pm 3.3$ & $16 \pm 1.4$ & - & - & - & - & - & - & - & - \\
\hline HCB & 0.075 & 37.5 & $17.9 \pm 11.6$ & $42 \pm 8.7$ & 3.75 & 37.5 & $4.5 \pm 2.3$ & $39.4 \pm 12.7$ & 0.075 & 30 & $16.4 \pm 2.1$ & $51.7 \pm 6.7$ \\
\hline$\alpha$-Chlordane & 0.4 & $50^{*}$ & $28.3 \pm 3.3$ & $15 \pm 1.1$ & - & - & - & - & 10 & 30 & $20.2 \pm 2.1$ & $7.4 \pm 12.5$ \\
\hline$o$-chlordane & 20 & $40^{*}$ & $26.5 \pm 19.4$ & $26.3 \pm 1.5$ & - & - & - & - & - & - & - & - \\
\hline t-nonachlor & 25 & $50^{*}$ & $34.3 \pm 1.8$ & $34.2 \pm 8.1$ & - & - & - & - & 25 & 25 & $16.8 \pm 2$ & $27.8 \pm 3.5$ \\
\hline$\gamma-\mathrm{HCH}$ & 0.5 & 50 & $27.5 \pm 2.7$ & $40.7 \pm 3.5$ & - & - & - & - & 50 & 75 & $61.2 \pm 2.9$ & $65.4 \pm 13.7$ \\
\hline Dieldrin & 6.25 & 50 & $22.4 \pm 11.4$ & $59.6 \pm 1.9$ & - & - & - & - & - & - & - & - \\
\hline BDE-47 & 0.25 & $20^{*}$ & $3.1 \pm 0.5$ & $17.9 \pm 2.7$ & 1.25 & 12.5 & ND & $55.3 \pm 7.2$ & - & - & - & - \\
\hline BDE-99 & 0.25 & 10 & $5.2 \pm 1.9$ & $36.3 \pm 1.5$ & - & - & - & - & - & - & - & - \\
\hline HBCD & 0.25 & 15 & $35.8 \pm 63.9^{* *}$ & $58.1 \pm 3.1$ & - & - & - & - & - & - & - & - \\
\hline
\end{tabular}

849 LOEC: lowest observed effect concentration $(p<0.05)$; MOEC: maximum observed effect concentration $(p<0.05)$; IC 50 : the concentration inducing half of the

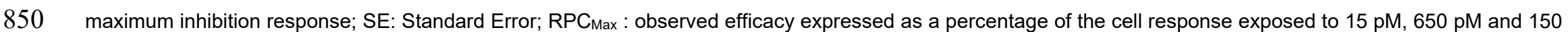

851 pM TCDD, respectively for DR-H4IIE, DR-Hep G2 and DR-T47-D, corresponding to the MOEC; ND: Not Determined. * Corresponds to the highest tested

852 concentration. ${ }^{* *} \mathrm{IC}_{50}$ estimated beyond tested concentrations. -: no response. 
Table 2.

\begin{tabular}{|c|c|c|c|c|c|c|c|c|c|c|c|c|}
\hline \multirow[t]{2}{*}{ Mixtures } & \multicolumn{4}{|c|}{ DR-H4IIE } & \multicolumn{4}{|c|}{ DR-Hep G2 } & \multicolumn{4}{|c|}{ DR-T47-D } \\
\hline & $\begin{array}{c}\text { LOEC } \\
(x \text { bl) }\end{array}$ & $\begin{array}{c}\text { MOEC } \\
(x \text { bl })\end{array}$ & $\begin{array}{c}\mathrm{IC}_{50} \pm \mathrm{SE} \\
(\mathrm{x} \text { bl })\end{array}$ & $\begin{array}{c}\mathrm{RPC}_{\operatorname{Max}} \\
(\%)\end{array}$ & $\begin{array}{c}\text { LOEC } \\
(x \text { bl) }\end{array}$ & $\begin{array}{c}\text { MOEC } \\
(x \text { bl })\end{array}$ & $\begin{array}{c}\mathrm{IC}_{50} \pm \mathrm{SE} \\
(\mathrm{x} \text { bl })\end{array}$ & $\begin{array}{c}\mathrm{RPC}_{\mathrm{Max}} \\
(\%)\end{array}$ & $\begin{array}{c}\text { LOEC } \\
(\mathrm{x} \text { bl) }\end{array}$ & $\begin{array}{c}\text { MOEC } \\
(x \text { bl) }\end{array}$ & $\begin{array}{c}\mathrm{IC}_{50} \pm \mathrm{SE} \\
(\mathrm{x} \text { bl) }\end{array}$ & $\begin{array}{c}\mathrm{RPC}_{\mathrm{Max}} \\
(\%)\end{array}$ \\
\hline POP & 125 & 1000 & $374 \pm 52$ & $52.5 \pm 2.1$ & 500 & 1000 & ND & $80.1 \pm 5.8$ & 250 & 1000 & ND & $86.6 \pm 2.2$ \\
\hline $\mathrm{Cl}$ & 250 & 1000 & $562 \pm 54$ & $53 \pm 0.9$ & 250 & 2000 & ND & $59 \pm 1.6$ & - & - & - & - \\
\hline $\mathrm{Cl}+\mathrm{Br}$ & 125 & 2000 & $468 \pm 38$ & $64.6 \pm 1.7$ & 500 & 1000 & $534 \pm 253$ & $76.1 \pm 3.9$ & - & - & - & - \\
\hline Cl+PFAA & 75 & 2000 & $461 \pm 78$ & $41 \pm 1.3$ & 500 & 500 & $243 \pm 104$ & $77 \pm 3.8$ & 500 & 500 & ND & $77 \pm 3.8$ \\
\hline
\end{tabular}

854 LOEC: lowest observed effect concentration ( $<<0.05$ ); MOEC: maximum observed effect concentration ( $p<0.05$ ); IC 50 : the concentration inducing half of the

855 maximum inhibition response; SE: Standard Error; $\mathrm{RPC}_{\mathrm{Max}}$ : relative response at MOEC expressed in \% of the response of TCDD EC $5015 \mathrm{pM}, 650 \mathrm{pM}$ and $150 \mathrm{pM}$

856 TCDD (respectively for DR-H4IIE, DR-Hep G2 and DR-T47-D) corresponding to the MOEC; $x$ bl: fold blood levels; ND: Not Determined. -: no response. 
Table S1: Composition of the total POP mixture and the six sub-mixtures (PFAA, Br, Cl, Cl+Br, Cl+PFAA, $\mathrm{Br}+\mathrm{PFAA})$. The minimum and maximum tested concentrations of each compound in individual compound testing and the concentrations of each compound corresponding to 1000 fold blood levels in the mixture testing are also given.

\begin{tabular}{|c|c|c|c|c|c|c|c|c|c|}
\hline \multirow[t]{2}{*}{ Compounds } & \multicolumn{2}{|c|}{$\begin{array}{l}\text { Individual compound testing: } \\
\text { tested concentration }(\mu \mathrm{M})\end{array}$} & \multicolumn{7}{|c|}{$\begin{array}{l}\text { Mixture testing: individual concentrations in the mixture corresponding to } \\
\qquad 1000 \text { fold blood levels }(\mu \mathrm{M})\end{array}$} \\
\hline & Minimum & Maximum & Total POP & PFAA & $\mathrm{Br}$ & $\mathrm{Cl}$ & $\mathrm{Cl}+\mathrm{Br}$ & Cl+PFAA & $\mathrm{Br}+\mathrm{PFAA}$ \\
\hline PCB-28 & 0.01 & 50 & 0.031 & & & 0.031 & 0.031 & 0.031 & \\
\hline PCB-52 & 0.01 & 50 & 0.021 & & & 0.024 & 0.021 & 0.021 & \\
\hline PCB-101 & 0.01 & 50 & 0.025 & & & 0.025 & 0.021 & 0.025 & \\
\hline PCB-118 & 0.01 & 50 & 0.14 & & & 0.13 & 0.12 & 0.13 & \\
\hline PCB-138 & 0.01 & 50 & 0.43 & & & 0.45 & 0.39 & 0.42 & \\
\hline PCB-153 & 0.01 & 50 & 0.70 & & & 0.73 & 0.63 & 0.67 & \\
\hline PCB-180 & 0.01 & 50 & 0.34 & & & 0.38 & 0.33 & 0.35 & \\
\hline$p, p^{\prime}-\mathrm{DDE}$ & 0.5 & 50 & 1.066 & & & 1.088 & 0.95 & 1.006 & \\
\hline HCB & 0.075 & 60 & 0.23 & & & 0.24 & 0.21 & 0.22 & \\
\hline$\alpha$-chlordane & 0.4 & 80 & 0.024 & & & 0.029 & 0.032 & 0.032 & \\
\hline o-chlordane & 0.4 & 40 & 0.34 & & & 0.034 & 0.029 & 0.029 & \\
\hline t-nonachlor & 0.5 & 50 & 0.099 & & & 0.099 & 0.101 & 0.101 & \\
\hline$\alpha-\mathrm{HCH}$ & 0.5 & 50 & 0.017 & & & 0.017 & 0.017 & 0.017 & \\
\hline$\beta-\mathrm{HCH}$ & 0.5 & 50 & 0.076 & & & 0.076 & 0.069 & 0.069 & \\
\hline$\gamma-\mathrm{HCH}$ & 0.5 & 100 & 0.017 & & & 0.021 & 0.017 & 0.017 & \\
\hline Dieldrin & 0.5 & 100 & 0.055 & & & 0.063 & 0.060 & 0.058 & \\
\hline BDE-47 & 0.025 & 20 & 0.019 & & 0.012 & & 0.016 & & 0.014 \\
\hline BDE-99 & 0.025 & 20 & 0.0071 & & 0.0053 & & 0.007 & & 0.0071 \\
\hline BDE-100 & 0.0025 & 1 & 0.0035 & & 0.0035 & & 0.004 & & 0.0035 \\
\hline BDE-153 & 0.0025 & 1 & 0.0016 & & 0.0016 & & 0.002 & & 0.0016 \\
\hline BDE-154 & 0.0025 & 1 & 0.0031 & & 0.0031 & & 0.003 & & 0.0016 \\
\hline BDE-209 & 0.0025 & 1 & 0.0094 & & 0.0104 & & 0.009 & & 0.0094 \\
\hline HBCD & 0.025 & 20 & 0.055 & & 0.055 & & 0.033 & & 0.065 \\
\hline PFHxS & 0.5 & 50 & 7.809 & 6.71 & & & & 7.41 & 6.91 \\
\hline PFOS & 0.5 & 50 & 41.52 & 18.19 & & & & 40.83 & 16.37 \\
\hline PFOA & 0.5 & 50 & 4.209 & 7.24 & & & & 4.42 & 6.69 \\
\hline PFNA & 0.5 & 50 & 1.092 & 1.76 & & & & 1.036 & 1.74 \\
\hline PFDA & 0.5 & 50 & 0.38 & 0.72 & & & & 0.44 & 0.66 \\
\hline PFUnDA & 0.5 & 50 & 0.34 & 0.32 & & & & 0.17 & 0.28 \\
\hline Summary co & tration $(\mu \mathrm{M})$ & & 59.048 & 34.94 & 0.091 & 3.43 & 3.101 & 57.51 & 32.75 \\
\hline
\end{tabular}

POPs: persistent organic pollutants. PFAA: perfluorinated compounds. Br: brominated compounds. Cl: chlorinated compounds. PCB: polychlorinated biphenyl. DDE: dichlorodiphenyldichloroethane. $\mathrm{HCB}$ : hexachlorobenzene. $\mathrm{HCH}$ : hexachlorocyclohexane. BDE: brominated diphenyl ether. HBCD: hexabromocyclododecane. PFHXS: perfluorohexanesulfonic acid. PFOS: perfluorooctanesulfonic acid. PFOA: perfluorooctanoic acid. PFNA: perfluorononanoic acid. PFDA: perfluorodecanoic acid. PFUnDA: perfluoroundecanoic acid. 
Table S2: $\mathrm{EC}_{50}, \mathrm{RPC}_{\mathrm{Max}}$ and relative potency for AhR agonistic compounds in DR-H4IIE and DR-T47-D cells $(n=3,0.2 \%$ DMSO).

\begin{tabular}{|l|lllll|ll|}
\hline Cell lines & \multicolumn{5}{|c|}{ DR-H4IIE } & \multicolumn{2}{c|}{ DR-T47-D } \\
\hline Compounds & BDE-99 & BDE-153 & BDE-154 & PCB-118 & PCB-138 & BDE-99 & y-HCH \\
\hline EC $_{50} \pm$ SE $(\mu \mathrm{M})$ & $4 \pm 0.8$ & ND & ND & $25 \pm 13$ & $28 \pm 6.4$ & $1.9 \pm 1.8$ & $>50$ \\
RPC $_{\text {Max }}(\%)$ & 7.3 & 15.2 & 8.9 & 61.3 & 28.2 & 11 & 6 \\
Relative potency & 0.0000038 & - & - & 0.00006 & 0.000054 & 0.000013 & 0.000033 \\
\hline
\end{tabular}

$\mathrm{EC}_{50}$ : concentration inducing half of the maximum response, extrapolated; $\mathrm{RPC}_{\mathrm{Max}}$ : observed efficicacy of the maximum tested concentration expressed in \% of the maximum response of TCDD; Relative potency: ratio between the $\mathrm{EC}_{50}$ of TCDD and the EC 50 of the tested compound, with TCDD EC $\mathrm{E}_{50}=15 \mathrm{pM}$ in DR-H4IIE and 150 pM in DR-T47D; SE: Standard Error; ND: not determined

Table S3: Four parameters obtained in the dose-response curves (Graphpad PRISM) of the 16 active

AhR antagonists in the rat DR-H4IIE cells $(n=3,0.2 \%$ DMSO, Mean \pm SD).

\begin{tabular}{|l|c|c|c|c|c|c|c|c|}
\hline Parameters & BDE-47 & BDE-99 & HBCD & PCB-28 & PCB-53 & PCB-101 & PCB-118 & PCB-138 \\
\hline Bottom (\%) & $0.2 \pm 7.05$ & $16.9 \pm 12.4$ & 0 & $20.3 \pm 7.4$ & $8.2 \pm 5.5$ & $47.2 \pm 7.4$ & $67.2 \pm 1.4$ & $43.1 \pm 1.5$ \\
\hline Top $(\%)$ & $100.7 \pm 2.6$ & $93.1 \pm 3.3$ & $80.7 \pm 1.4$ & $104.2 \pm 1.8$ & $107.6 \pm 1.2$ & $99.5 \pm 1.3$ & $104.2 \pm 1.8$ & $92.9 \pm 2.1$ \\
\hline HillSlope & $0.9 \pm 0.1$ & $0.9 \pm 0.2$ & $1.3 \pm 0.5$ & $1.1 \pm 0.2$ & $1.1 \pm 0.1$ & $1.5 \pm 0.3$ & $2.2 \pm 0.5$ & $2.4 \pm 0.6$ \\
\hline IC50 $(\mu \mathrm{M})$ & $3.1 \pm 0.5$ & $5.2 \pm 1.9$ & $35.8 \pm 63.9$ & $6.8 \pm 1.7$ & $7.3 \pm 1.2$ & $17.9 \pm 3.8$ & $0.3 \pm 0.05$ & $0.6 \pm 0.07$ \\
\hline Parameters & PCB-153 & PCB-180 & HCB & $\alpha$-Chlordane & o-chlordane & $t$-nonachlor & $\gamma$-HCH & Dieldrine \\
\hline Bottom $(\%)$ & 0 & $5.1 \pm 14.7$ & $33.01 \pm 13.4$ & 0 & 0 & $25.8 \pm 5.8$ & $23.2 \pm 4.6$ & $45.6 \pm 11.5$ \\
\hline Top $(\%)$ & $89.9 \pm 1.1$ & $102.9 \pm 3.2$ & $74.6 \pm 2.6$ & $89.1 \pm 1.2$ & $101.4 \pm 4.8$ & $89 \pm 1.0$ & $94.4 \pm 1.6$ & $96.7 \pm 3.3$ \\
\hline HillSlope & $1.4 \pm 0.2$ & $0.9 \pm 0.2$ & $1.1 \pm 0.5$ & $2.4 \pm 0.4$ & $2.2 \pm 1.5$ & $4.98 \pm 0.9$ & $1.8 \pm 0.3$ & $0.8 \pm 0.3$ \\
\hline IC50 $(\mu \mathrm{M})$ & $18.5 \pm 2.8$ & $7.4 \pm 3.3$ & $17.9 \pm 11.6$ & $28.3 \pm 3.3$ & $26.5 \pm 19.4$ & $34.3 \pm 1.8$ & $27.5 \pm 2.7$ & $22.4 \pm 11.4$ \\
\hline
\end{tabular}


Table S4: Measured and predicted bottom, hillslope and $\mathrm{IC}_{50}$ of the CA models with several methods for the total POP mixture and $\mathrm{Cl}, \mathrm{Cl}+\mathrm{Br}, \mathrm{Cl}+\mathrm{PFAA}$ sub-mixtures.

\begin{tabular}{|l|c|c|c|c|c|c|}
\hline Methods & Measured & WMBH & AvBH & FoBH & sNA WMBH & sNA FoBH \\
\hline \multicolumn{7}{|c|}{ Total POP mixture } \\
\hline Bottom (\%) & 52.5 & 5 & 21 & 0 & 100 & 0 \\
\hline Hillslope & 1.3 & 0.5 & 1.7 & 34.2 & -10.9 & 1.5 \\
\hline IC 50 (x bl) & 374 & 784 & 784 & 784 & 784 & 784 \\
\hline \multicolumn{7}{|l|}{ Cl sub-mixture } \\
\hline Bottom (\%) & 53 & 83 & 25 & 0 & 100 & 0 \\
\hline Hillslope & 2.1 & 6.9 & 1.8 & 2.1 & -10.6 & 1.4 \\
\hline IC50 (x bl) & 500 & 786 & 786 & 786 & 786 & 786 \\
\hline \multicolumn{7}{|l|}{ Cl+Br mixture } \\
\hline Bottom (\%) & 64.6 & 83 & 21 & 0 & 100 & 0 \\
\hline Hillslope & 2.1 & 7 & 1.7 & 2.1 & -10.6 & 1.4 \\
\hline IC50 (x bl) & 500 & 875 & 875 & 875 & 875 & 875 \\
\hline \multicolumn{7}{|c|}{ Cl+PFAA mixture } \\
\hline Bottom (\%) & 41 & 5 & 25 & 0 & 100 & 0 \\
\hline Hillslope & 1.4 & 0.4 & 1.8 & 38.6 & -10.7 & 1.4 \\
\hline IC50 (x bl) & 576 & 840 & 840 & 840 & 840 & 840 \\
\hline
\end{tabular}

$\mathrm{WMBH}=$ weighted mean, $\mathrm{AvBH}=$ averaged, formulated hillslope and bottom $(\mathrm{FoBH}), \mathrm{sNA}=$ substracted nonactive compounds. $x$

bl: fold blood levels. 
Figure S1: Dose-response curves obtained from DR-H4IIE cells co-exposed to 15 pM TCDD (solid lines) or $20 \mathrm{nM}$ TCDD (dashed lines) and PCBs (A1 and A2), OCPs (B1 and B2) and BRFs (C) (Mean \pm SD, $n=$ $3,0.3 \%$ DMSO).

(A1) PCBs

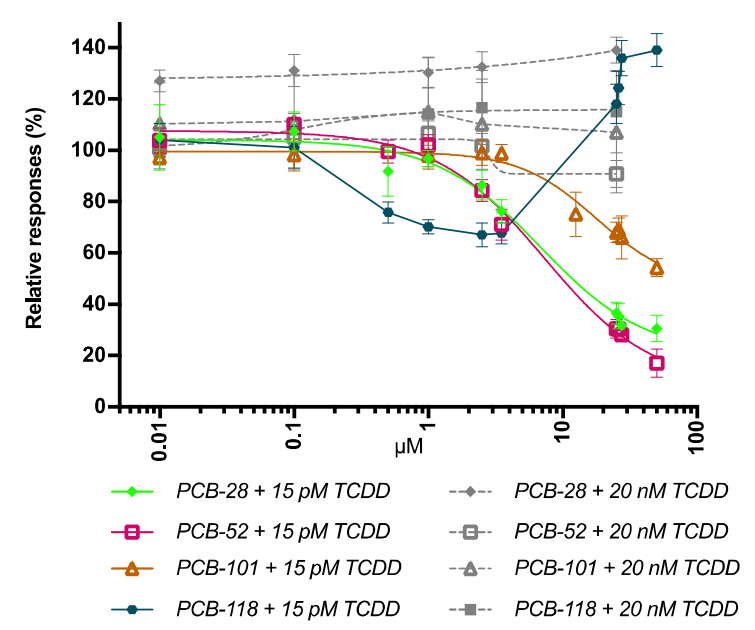

(B1) OCPs

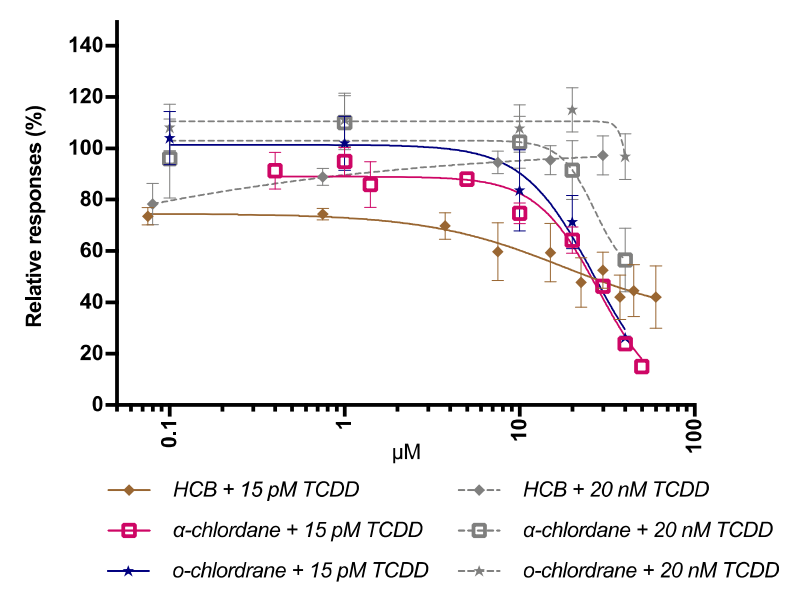

(C) BFRs

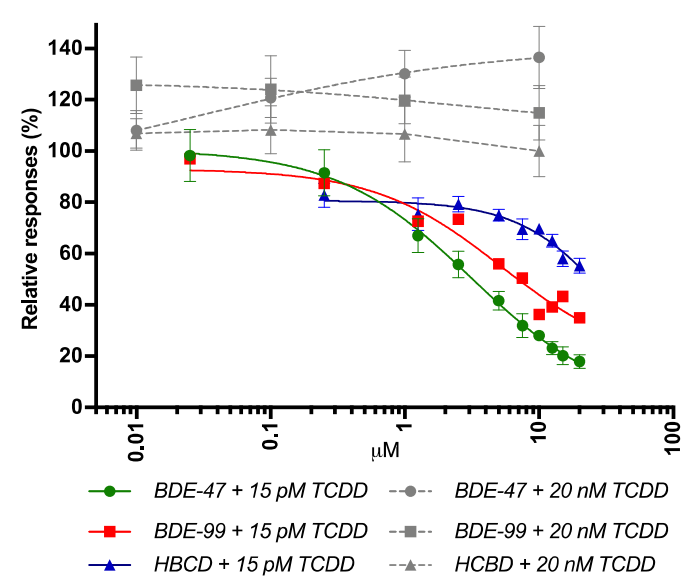

(A2) PCBs

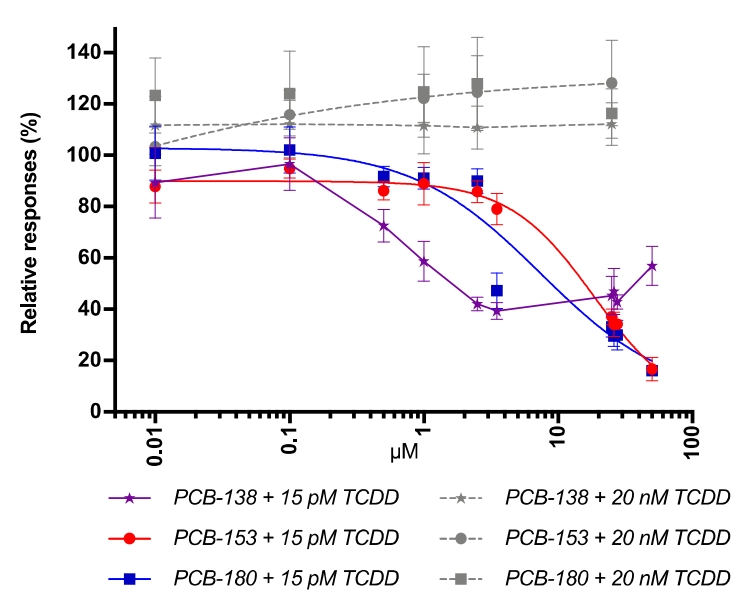

(B2) OCPs

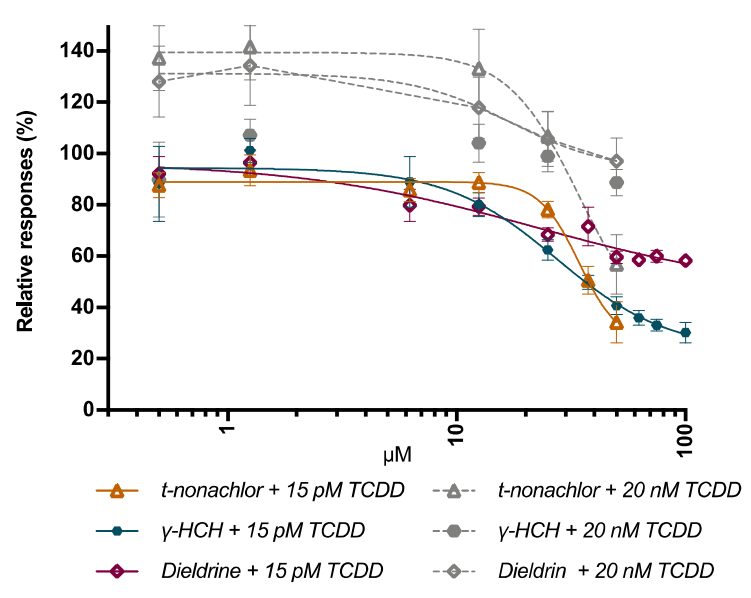


Figures S2: Predicted full dose-response curves of the concentration addition models with several methods to calculate the bottom and hill-slope for the total POP mixture (A) and $\mathrm{Cl}(\mathrm{B}), \mathrm{Cl}+\mathrm{Br}(\mathrm{C}), \mathrm{Cl}+\mathrm{PFAA}(\mathrm{D})$ submixtures. $\mathrm{WMBH}=$ weighted mean, $\mathrm{AvBH}=$ averaged, formulated hillslope and bottom, $\mathrm{sNA}=$ subtracted nonactive compounds.

(A)
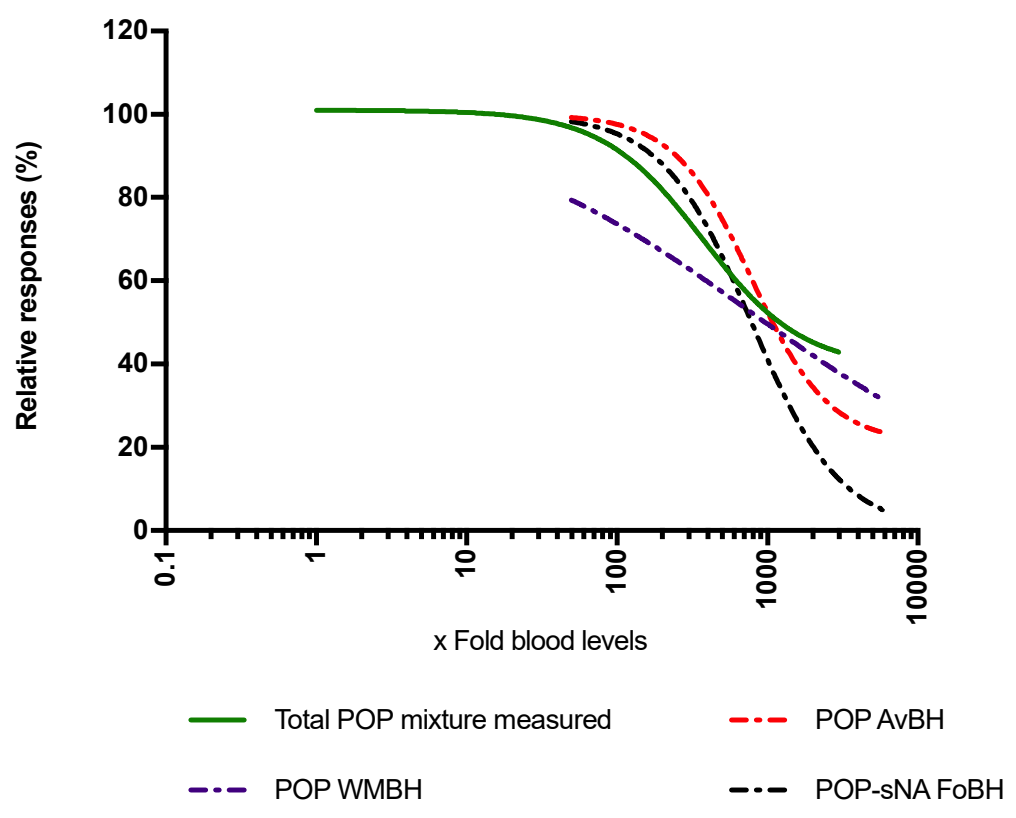

(B)

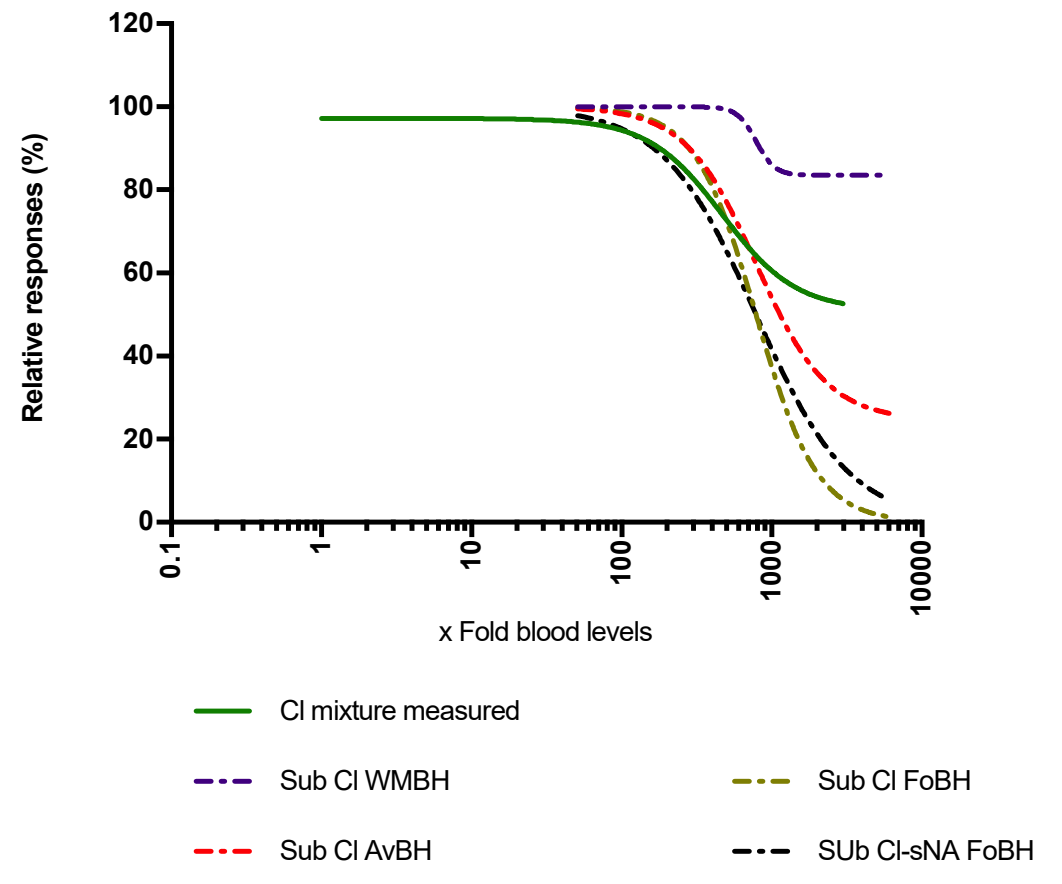


(C)

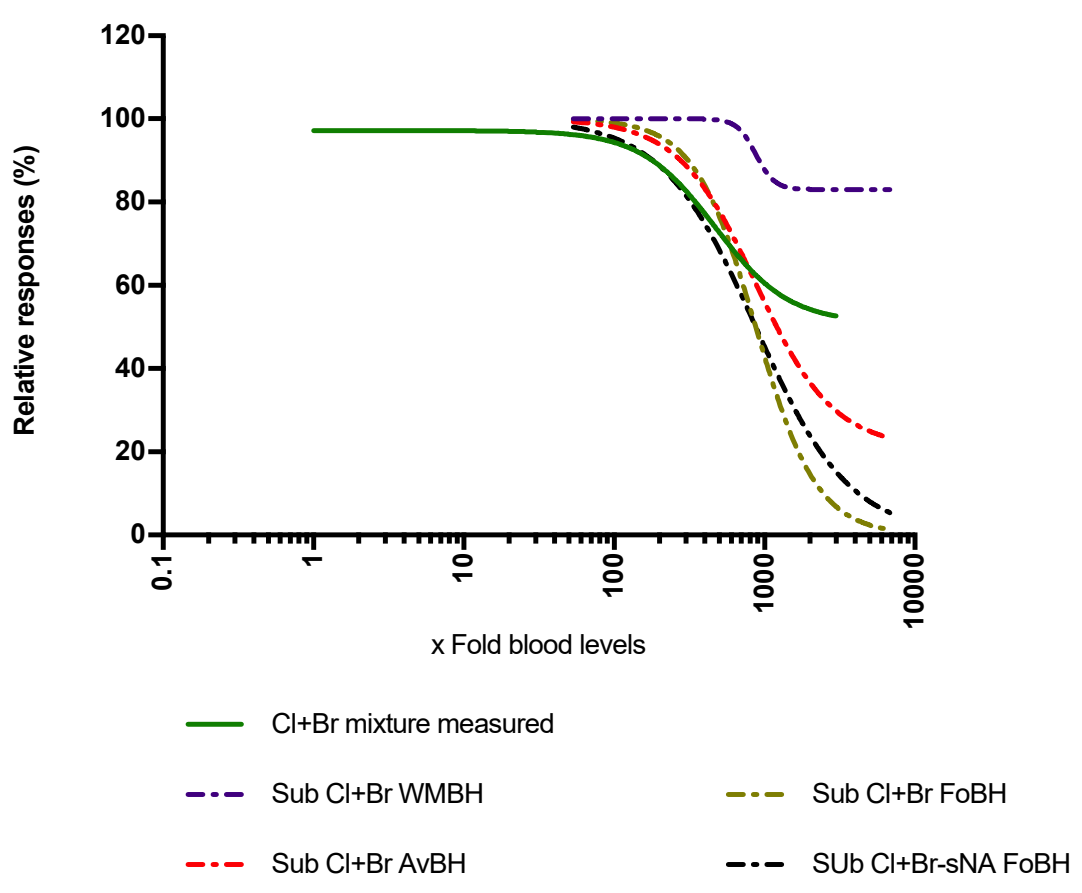

(D)

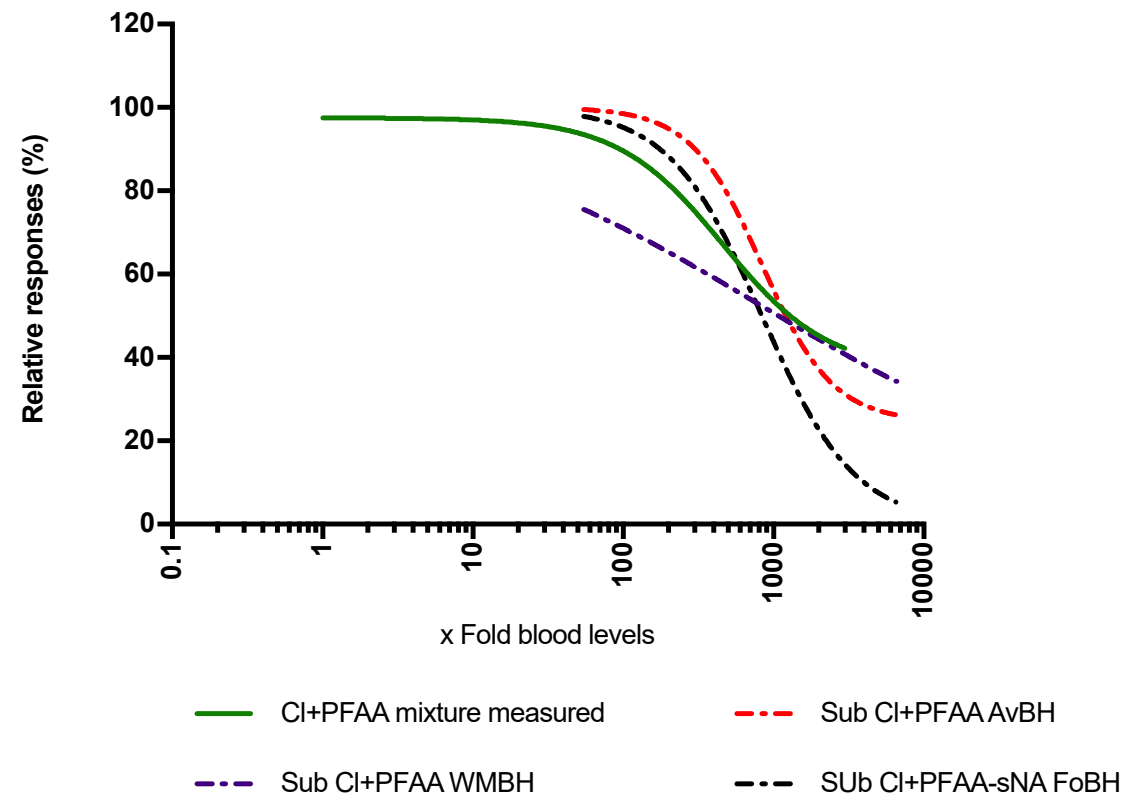

